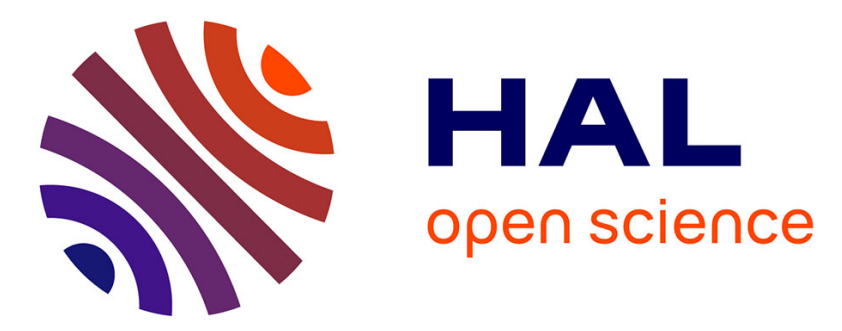

\title{
Large-scale geographic survey provides insights into the colonization history of a major aphid pest on its cultivated apple host in Europe, North America and North Africa
}

S.G. Olvera-Vazquez, C. Remoue, A. Venon, A. Rousselet, O. Grandcolas, M. Azrine, L. Momont, M. Galan, L. Benoit, G. David, et al.

\section{To cite this version:}

S.G. Olvera-Vazquez, C. Remoue, A. Venon, A. Rousselet, O. Grandcolas, et al.. Large-scale geographic survey provides insights into the colonization history of a major aphid pest on its cultivated apple host in Europe, North America and North Africa. 2021. hal-03098912

\section{HAL Id: hal-03098912 https://hal.science/hal-03098912}

Preprint submitted on 6 Jan 2021

HAL is a multi-disciplinary open access archive for the deposit and dissemination of scientific research documents, whether they are published or not. The documents may come from teaching and research institutions in France or abroad, or from public or private research centers.
L'archive ouverte pluridisciplinaire HAL, est destinée au dépôt et à la diffusion de documents scientifiques de niveau recherche, publiés ou non, émanant des établissements d'enseignement et de recherche français ou étrangers, des laboratoires publics ou privés. 
1 Large-scale geographic survey provides insights into the colonization history of a major

4 Olvera-Vazquez S.G. ${ }^{1}$, Remoué C. ${ }^{1}$, Venon A. ${ }^{1}$, Rousselet A. ${ }^{1}$, Grandcolas O. ${ }^{1}$, Azrine M. ${ }^{1}$,

5 Momont L. ${ }^{1}$, Galan M. ${ }^{2}$, L. Benoit ${ }^{2}$, David G. ${ }^{3}$, Alhmedi A. ${ }^{4}$, Beliën T. ${ }^{4}$, Alins G. ${ }^{5}$, Franck

$6 \quad$ P. $^{6}$, Haddioui A. ${ }^{7}$, Jacobsen S.K. ${ }^{8}$, Andreev R. ${ }^{9}$, Simon S. ${ }^{10}$, Sigsgaard L. ${ }^{8}$, Guibert E. ${ }^{11}$,

7 Tournant L. ${ }^{12}$, Gazel F. ${ }^{13}$, Mody K. ${ }^{14}$, Khachtib Y. ${ }^{7}$, Roman A. ${ }^{15}$, Ursu T.M. ${ }^{15}$, Zakharov I.A.

$8{ }^{16}$, Belcram H. ${ }^{1}$, Harry M. ${ }^{17}$, Roth M. ${ }^{18}$, Simon J.C. ${ }^{19}$, Oram S. ${ }^{20}$, Ricard J.M. ${ }^{11}$, Agnello A. ${ }^{21}$,

9 Beers E. H. ${ }^{22}$, Engelman J. ${ }^{23}$, Balti I. ${ }^{24}$, Salhi-Hannachi A ${ }^{24}$, Zhang H. ${ }^{25}$, Tu H. ${ }^{25}$, Mottet C. ${ }^{26}$,

10 Barrès B. ${ }^{26}$, Degrave A. ${ }^{27}$, Razmjou J. ${ }^{28}$, Giraud T. ${ }^{3}$, Falque M. ${ }^{1}$, Dapena E. ${ }^{29}$, Miñarro, M. ${ }^{29}$,

11 Jardillier L. ${ }^{3}$, Deschamps P. ${ }^{3}$, Jousselin E. ${ }^{2}$, Cornille, A. ${ }^{1}$

13 1. Université Paris Saclay, INRAE, CNRS, AgroParisTech, GQE - Le Moulon, 91190

14 Gif-sur-Yvette, France

15 2. INRAE, UMR 1062, Centre de Biologie pour la Gestion des Populations CBGP

16 (INRAE, IRD, CIRAD, Montpellier SupAgro), Montferrier-sur-Lez, 34980, France.

17 3. Ecologie Systematique et Evolution, CNRS, AgroParisTech, Université Paris-Saclay,

1891400 , Orsay, France

19 4. Department of Zoology, Fruit Research Center (pcfruit npo), Sint-Truiden, Belgium.

20 5. Institut de Recerca i Tecnologia Agroalimentàries, IRTA-Fruit Production, PCiTAL, Parc

21 de Gardeny, edifici Fruitcentre, 25003 Lleida, Spain

22 6. INRAE, UR1115, Plantes et Système de cultures Horticoles (PSH), Agroparc CS 40509,

23 Avignon, F-84000, France.

24 7. Laboratory of Biotechnology and Valorisation of Plant Genetic Resources, Faculty of

25 Sciences and Techniques, University of Sultan Moulay Slimane, Beni Mellal, Morocco 
26 8. Department of Plant and Environmental Sciences, University of Copenhagen, Denmark.

27 9. Department of Entomology, Agricultural University, Plovdiv, Bulgaria.

28 10. Unité Expérimentale UERI 695, INRAE, 460 Chemin de Gotheron, F-26320 Saint-

29 Marcel-lès-Valence, France

30 11. CTIFL, Centre opérationnel de Balandran

31 12. Fédération Régionale de Défense contre les Organismes Nuisibles Nord Pas-de-Calais,

32 Loos-en-Gohelle, France

33 13. BORDX ARBORI UE - Unité d'arboriculture

34 14. Department of Applied Ecology, Hochschule Geisenheim University, Geisenheim,

35 Germany

36 15. Institute of Biological Research Cluj, Branch of National Institute of Research and

37 Development for Biological Sciences (NIRDBS), 400015, Cluj-Napoca, Romania.

38 16. Vavilov Institute of General Genetics RAS, Moscow, Russia

39 17. Laboratoire Évolution, Génomes, Comportement, Écologie, UMR9191

40 CNRS/IRD/Université Paris-Saclay, Gif-sur-Yvette, France

41 18. GAFL, INRAE, 84140, Montfavet, France

42 19. INRAE, UMR IGEPP, Domaine de la Motte, Le Rheu, France

43 20. People's Trust for Endangered Species, London, UK

44 21. Department of Entomology, Cornell AgriTech, Cornell University, Geneva, NY

45 22. Department of Entomology, Tree Fruit Research and Extension Center, Washington State

46 University, Wenatchee, WA

47 23.Virginia Tech, Alson H. Smith, Jr. Agricultural Research and Extension Center, 595

48 Laurel Grove Road, Winchester, VA 22602, USA 
49 24. Department of Biology, Faculty of Science of Tunis, University of Tunis El Manar, 2092,

50 Tunis, Tunisia, Salhi-Hannachi A: Department of Biology, Faculty of Science of Tunis,

51 University of Tunis, Tunisia.

52 25. Zhengzhou Fruit Research Institute, Chinese Academy of Agricultural Sciences, 450009,

53 Zhengzhou, China.

54 26. Université de Lyon, Anses, INRAE, USC CASPER, 69007 Lyon, France

55 27. IRHS, INRAE, Agrocampus-Ouest, Université d'Angers, SFR 4207 QUASAV,

56 Beaucouzé, France

57 28. Department of Plant Protection, Faculty of Agriculture and natural Resources, University

58 of Mohaghegh Ardabili, Iran

59 29. Servicio Regional de Investigación y Desarrollo Agroalimentario, Ctra. AS-267, PK 19,

60 E-33300, Villaviciosa, Asturias, Spain

61

62 Corresponding author: amandine.cornille@inrae.fr

63

64

65 


\section{Summary}

67 With frequent host shifts involving the colonization of new hosts across large geographical

68 ranges, crop pests are good models for examining the mechanisms of rapid colonization. The

69 microbial partners of pest insects may be involved or affected by colonization, which has

70 been little studied so far. We investigated the demographic history of the rosy apple aphid,

71 Dysaphis plantaginea, a major pest of the cultivated apple (Malus domestica) in Europe,

72 North Africa and North America, as well as the diversity of its endosymbiotic bacterial

73 community. We genotyped a comprehensive sample of 714 colonies from Europe, Morocco

74 and the US using mitochondrial ( $C y t B$ and $C O 1$ ), bacterial (16s rRNA and TrnpB), and 30

75 microsatellite markers. We detected five populations spread across the US, Morocco,

76 Western and Eastern Europe, and Spain. Populations showed weak genetic differentiation and

77 high genetic diversity, except the Moroccan and the North American that are likely the result

78 of recent colonization events. Coalescent-based inferences releaved high levels of gene flow

79 among populations during the colonization, but did not allow determining the sequence of

80 colonization of Europe, America and Morroco by D. plantaginea, likely because of the weak

81 genetic differentiation and the occurrence of gene flow among populations. Finally, we found

82 that $D$. plantaginea rarely hosts any other endosymbiotic bacteria than its obligate nutritional

83 symbiont Buchnera aphidicola. This suggests that secondary endosymbionts did not play any

84 role in the rapid spread of the rosy apple aphid. These findings have fundamental importance

85 for understanding pest colonization processes and implications for sustainable pest control

86 programs.

88 Keywords: colonization, expansion, pest, apple, aphid, endosymbiotic bacteria, Buchnera, 89 gene flow, ABC-RF. 


\section{$91 \quad$ Introduction}

92

Understanding the evolutionary processes underlying the colonization of new environments and the range expansion of species is a key goal in evolutionary biology (Angert, Bontrager, \& Ågren, 2020; Austerlitz, Jung-Muller, Godelle, \& Gouyon, 1997; Excoffier, Foll, \& Petit, 2009; Hoffmann \& Courchamp, 2016; Rius \& Darling, 2014). Crop parasites, with their frequent shifts in hosts involving the colonization of new hosts across large geographic ranges, are good models to study the mechanisms of rapid colonization and range expansion (Garnas et al., 2016; Gladieux et al., 2014; Stukenbrock \& McDonald, 2008). The key questions relating to the evolutionary processes underlying the colonization, spread and success of crop parasites pertain to the geographic origin of the source population, the location of the migration routes, the extent to which genetic diversity is reduced via founder effects (Blakeslee et al., 2019) and the extent of gene flow among populations during the spread of the crop parasite (Stukenbrock, 2016). Current and future threats to biodiversity and their consequences on ecosystem health and services make these questions more relevant than ever. Understanding the routes of pest colonization contributes greatly to the efforts to protect crops against future pest emergence and therefore has direct implications for breeding and agronomic programs, that use crops and develop biological methods of parasite control (Estoup \& Guillemaud, 2010; Fraimout et al., 2017; Lawson Handley et al., 2011; Turcotte, Araki, Karp, Poveda, \& Whitehead, 2017).

Historically, gene genealogies have been a rich source of information into a species' evolutionary history that could be applied to the study of colonization (Bloomquist, Lemey, \& Suchard, 2010; Hickerson et al., 2010; Posada \& Crandall, 2001). The characterization of population structure, genetic diversity and demographic history (divergence time, migration rates among populations, and effective population size) are also essential to understand the evolutionary processes underlying rapid colonization and range of geographic expansion 
117 (Excoffier et al., 2009). Approximate Bayesian computation methods (referred to as "ABC"

118 hereafter) provide a robust framework for inferring a species' history by allowing the

119 comparison of alternative demographic models and the estimation of their associated

120 parameters (divergence time, migration rate, effective population size) (Bertorelle, Benazzo,

121 \& Mona, 2010; Csillery, Blum, \& Francois, 2012; Csilléry, Blum, Gaggiotti, \& François,

122 2010; Estoup, Raynal, Verdu, \& Marin, 2018; Raynal et al., 2019; Roux \& Pannell, 2015).

123 The power of the ABC methods has made it possible to retrace the evolutionary history of 124 notorious crop pathogens (e.g., Plasmopara viticola (Berk \& Curtis) Berl. \& de Toni 125 (Fontaine et al., 2020), Microbotryum lychnidis-dioicae (DC. Ex Liro) G. Deml \& Oberw. 126 (Gladieux et al., 2015)), insect crop pests (e.g., Batrocera dorsalis Hendel (Aketarawong et 127 al., 2014), Drosophila suzukii Matsumura (Fraimout et al., 2017), Daktulosphaira vitifoliae 128 Fitch (Rispe et al., 2020)) and invasive alien species posing a threat to the native fauna (e.g., 129 Harmonia axyridis Pallas (Lawson Handley et al., 2011)). These studies have identified the 130 source populations, reconstructed complex colonization routes and determined the pace of 131 geographic range expansion, often emphasizing the role of human transportation in the spread 132 of these noxious species. Recently, the $\mathrm{ABC}$ approach, combined with machine learning (i.e., 133 random forest, referred to as “ABC-RF” hereafter, (Estoup et al., 2018; Raynal et al., 2019)), 134 was used to demonstrate that the African arid-adapted locust pest species Schistocerca 135 gregaria Forsskål colonized Africa through major migration events driven by the last glacial 136 climatic episodes (Chapuis et al., 2020). Yet, ABC methods are underused for estimating the 137 extent of gene flow during parasite colonization (but see (Fraimout et al., 2017)). Most 138 studies assume punctual admixture events among populations, but rarely continuous gene 139 flow per generation among populations. Only recently has the new ABC-RF approach been 140 used to infer the invasion routes, evolutionary history and extent of gene flow in the spotted141 wing D. suzukii Matsumura from microsatellite markers (Fraimout et al., 2017) (referred to as 
142 SSR for simple sequence repeat hereafter). Beyond population genomics approaches, and in

143 the special case of insect pests, the investigation of colonization history could also benefit

144 from the characterization of insect endosymbiotic bacterial communities. Indeed, many insect

145 pests host a consortium of endosymbiotic bacteria that mediate their adaptation to new

146 environmental conditions (Frago, Zytynska, \& Fatouros, 2020). Variations in the

147 endosymbiotic consortium along colonization routes could facilitate the rapid adaptation of

148 insect pests to different environments (Lenhart \& White, 2020) and therefore its spread.

149 Alternatively, if the colonization stems from only a few populations, it might actually be

150 accompanied by a loss of endosymbiont diversity along the colonization routes.

151 Aphids provide a model system for the study of the evolutionary biology and ecology

152 of insect pests. These major pests infest a wide range of host species, in particular crop plants

153 (Blackman \& Eastop, 2000). Some aphid species have now become cosmopolitan following

154 the dissemination of crops around the globe (Brady et al., 2014; Kirk, Dorn, \& Mazzi, 2013;

155 Zepeda $\square$ Paulo et al., 2010; Zhang, Edwards, Kang, \& Fuller, 2014). Aphids are therefore a

156 good study system to investigate the evolutionary processes involved in range expansion and

157 the colonization of new environments. The clonal reproduction of aphids during spring and

158 summer is one of the reasons put forward to account for their remarkable success worldwide.

159 Indeed, asexual reproduction allows for a rapid increase in population size after the

160 colonization of a favorable new environment (Simon, Rispe, \& Sunnucks, 2002; Simon,

161 Stoeckel, \& Tagu, 2010). So far, only a handful of studies have reconstructed the colonization

162 history of aphid crop pests by combining population genetics approaches using SSR as well

163 as sequence and single nucleotide polymorphism (SNP) markers (Fang, Chen, Jiang, Qu, \&

164 Qiao, 2018; Giordano et al., 2020; Kim, Hoelmer, \& Lee, 2016; Morales $\square$ Hojas, Sun,

165 Iraizoz, Tan, \& Chen, 2020; Peccoud et al., 2008; Piffaretti et al., 2013; Zepeda $\square$ Paulo et al.,

166 2010; Zhang et al., 2014, 2014; Zhou et al., 2015). These studies demonstrated that aphid 
167 species can spread very quickly across the world, probably via plants transported by humans 168 and/or wind dispersal. Colonization was found to involve several populations with high 169 genetic diversity, possibly with gene flow (Wang, Hereward, \& Zhang, 2016; Wei, Zuorui, 170 Zhihong, \& Lingwang, 2005) and/or a few "super-clones", i.e., predominant genotypes 171 widespread in space and time (Vorburger, Lancaster, \& Sunnucks, 2003)), which are highly 172 differentiated from each other and have high dispersal capacities (Piffaretti et al., 2013).

173 Assessing the genetic diversity and structure, the extent of gene flow among populations in 174 aphids are therefore central to determining the evolutionary processes that have taken place 175 during aphid colonization.

176 It can be interesting to associate the reconstruction of aphid colonization history with 177 the characterization of their endosymbiotic bacterial community. Aphids indeed harbor both 178 obligate symbionts that supply them with the nutrients that are missing from their diet 179 (Buchner, 1965) and facultative symbionts that can provide various selective advantages in 180 specific environmental conditions (Haynes et al., 2003; Oliver, Degnan, Burke, \& Moran, 181 2010). The aphid obligate endosymbiont bacterium Buchnera aphidicola has strictly 182 cospeciated with most aphid species (Jousselin, Desdevises, \& Coeur d'acier, 2009).

183 Bacterial markers (e.g., TrpB), along with typical other markers (e.g., CO1 or Cytb for 184 instance), can be used to infer the phylogenetic history of aphid species and to investigate 185 signal of recent range expansions (Popkin et al., 2017; Zhang et al., 2014). Beyond the use of 186 bacterial genomes as a way to reconstruct aphid phylogeography, the study of the 187 composition of the bacterial populations in aphids might also help assessing the importance 188 of facultative bacteria for colonizing new geographic regions. Many studies have investigated 189 the variation in bacterial communities associated with the pea aphid (Acyrthosiphon pisum 190 Harris), showing geographical variation, host-specific differentiation and also an association 191 with environmental factors such as temperature (Russell et al., 2013; Tsuchida, Koga, Shibao, 
192 Matsumoto, \& Fukatsu, 2002; Zepeda-Paulo, Ortiz-Martínez, Silva, \& Lavandero, 2018). The

193 effect of endosymbionts on aphid fitness has been confirmed experimentally in certain cases

194 (e.g., (Frago et al., 2017; Leclair et al., 2016). Nevertheless, studies on a global scale in non-

195 model aphid species are still scarce (Zytynska \& Weisser, 2016), and there are as of yet no

196 studies simultaneously investigating the migration routes of an aphid species and the changes

197 in symbiotic associations along this route.

198 Dysaphis plantaginea Passerini, the rosy apple aphid, is one of the most harmful

199 aphid pests attacking cultivated apple trees (Malus domestica Borkh), causing major

200 economic losses every year, especially in Europe, North Africa and North America

201 (Guillemaud, Blin, Simon, Morel, \& Franck, 2011; Warneys et al., 2018; Wilkaniec, 1993).

202 This aphid species occurs across temperate regions (Central and Southwest Asia, North

203 Africa, America, and Europe) (Blackman \& Eastop, 2000) in cultivated apple orchards. The

204 rosy apple aphid completes its life cycle on two successive host plants: the cultivated apple

205 trees as its sole primary host plant, from early autumn to late spring, and the plantain herb

206 Plantago spp. as a secondary host plant during summer (Bonnemaison, 1959). The rosy apple

207 aphid reproduces via asexual reproduction (parthenogenesis) and sexual reproduction, the

208 latter takes place in autumn when females lay fertilized overwintering eggs on apple trees.

209 Eggs hatch in early spring (Blommers, Helsen, \& Vaal, 2004). The rosy apple aphid is

210 closely related to other aphid genera found on fruit trees, namely the genus Myzus, Aphis and

211 Brachycaudus (Choi, Shin, Jung, Clarke, \& Lee, 2018; Coeur d'acier et al., 2014). While its

212 phylogenetic relationships with other aphid species is quite well resolved, the evolutionary

213 history of D. plantaginea has been little explored to date (but see (Guillemaud et al., 2011)).

214 The native range of $D$. plantaginea and its ancestral host range is not known. It might have

215 been ancestrally associated with Malus sieversii, the primary ancestor of the cultivated apple

216 (M. domestica) (Harris, Robinson, \& Juniper, 2002), and then colonized Europe during the 
217 journey of the cultivated apple along the Silk Routes from Asia to Europe. Alternatively, the

218 rosy apple aphid may have colonized its cultivated apple host in Europe rapidly and recently,

219 about 1,500 years ago when the Greeks brought the cultivated apple to Europe from Central

220 Asia (Cornille et al., 2019; Cornille, Giraud, Smulders, Roldán-Ruiz, \& Gladieux, 2014).

221 These scenarios are derived from our knowledge of the domestication history of apples; there

222 is no data on the rosy apple aphid that supports these scenarios. The migration routes of the

223 rosy apple aphid are therefore still unknown. Only some historical records show that the

224 introduction of the rosy apple aphid was very recent in America (ca. 1890s) (Foottit, Halbert,

225 Miller, Maw, \& Russell, 2006). More generally, the population structure and the extent of

226 gene flow among populations throughout the geographic distribution of $D$. plantaginea is

227 largely unknown, especially in the regions where it causes the most damages in apple

228 orchards, i.e., North America, North Africa and Europe. There is also no data so far on the

229 diversity of endosymbionts across a large geographical range in aphids.

230 Here, we therefore investigated the colonization history of this major fruit tree pest

231 using multiple approaches and genetic datasets, sampling from comprehensive collections

232 from Europe, North America and Morocco, on the primary host, the cultivated apple. Note

233 that, despite repeated attempts, we failed to sample $D$. plantaginea from its putative source

234 population in Central Asia, in the center of origin of apple trees, preventing to fully address

235 its colonization history starting from there. Therefore, we aimed to answer the following

236 questions focusing on the most damaged regions by the rosy apple aphid, i.e., Europe, North

237 America and North Africa: i) What is the spatial genetic diversity and population structure of

238 D. plantaginea across Europe, the US and Morocco? Can we detect genetically diverse

239 populations, and/or recent bottlenecks in colonizing populations? ii) Did gene flow occur

240 among populations during colonization? iii) Did D. plantaginea populations loose or gain

241 symbionts during their colonization? 


\section{Material and Methods}

\section{Samples and DNA extraction}

245 Each sample described hereafter consisted of a single aphid colony of 10-15 females

246 collected on a host plant during the spring of 2017 and 2018. Sampling only one colony per

247 tree ensured that the sample did not contain different clones, which can occur on the same

248 tree. Each colony was kept in ethanol $(96 \%)$ at $-20^{\circ} \mathrm{C}$ until DNA extraction. For the three

249 methods described below (i.e., SSR genotyping, Sanger sequencing of the aphid

250 mitochondrial CO1, Cytb markers, and $\operatorname{TrpB}$ bacterial marker, and metabarcoding of the $16 \mathrm{~S}$

251 rRNA bacterial marker), DNA was isolated from a single individual per colony using a new

252 standardized protocol (Supplementary material Text S1). For the sake of simplicity, colonies

253 are referred to as 'individuals' or 'samples' hereafter. Note that samples used for 16S rRNA

254 sequencing underwent two extra chemical washes before DNA extraction to remove the

255 external bacteria that could be present on the aphid's cuticle. The extra chemical washes

256 consisted of a first wash with dithiothreitol/DTT $(50 \mathrm{mM})$ for 4 minutes, followed by a

257 second wash with potassium hydroxide/ $\mathrm{KOH}(200 \mathrm{mM})$ for 4 minutes. The $\mathrm{KOH}$ wash was

258 performed twice. Five controls were also included ((Jousselin et al., 2016), Table S1).

259 Different sample sizes were used for each of the three methods (i.e., SSR genotyping,

260 metabarcoding of the $16 \mathrm{~S}$ rRNA bacterial marker, Sanger sequencing of the aphid CO1, Cytb

261 and $\operatorname{Trp} B$ markers). For each sample, the locality, sample collector identity, host plant

262 species, latitude, longitude and use in this study (genotyping, Sanger sequencing and/or

263 metabarcoding) are given in Table S1.

264 The largest sample was collected for SSR genotyping, comprising 667 D. plantaginea

265 samples (colonies) from Europe, Morocco and the US, from three hosts: M. domestica (50

266 sites, i.e., orchards, $N=654$ ), but also M. sylvestris (one site, Alta Ribagorça in Spain, $N=7$ ), 
267 the European wild apple, and P. lanceolata (one site, Loos-en-Gohelle in France, $N=6$ ). The

268667 samples originated from 52 different geographic sites (i.e., 52 orchards) spread over 13

269 countries; seven to 15 individuals were collected at each site (Table S1, Figure S1). We tried

270 to obtain samples from Eastern Asia and Central Asia during fieldwork in 2017 and 2018,

271 and through our collaborative network. However, despite our attempts and although $D$.

272 plantaginea is referenced in the literature on various hosts in several Central Asian countries

273 (Aslan \& Karaca, 2005; CAB International, 2020; Holman, 2009), it was not observed in 274 these areas.

275 For the investigation of the bacterial 16S rRNA region, we used 178 D. plantaginea

276 individuals out of the same 667 colonies used for SSR genotyping (Table S1). We selected

277 two to three samples (colonies) per site to cover a wide and even spatial distribution across

278 Europe, North America and Morocco. The selected 178 individuals were collected across 12

279 countries on M. domestica, except eight on M. sylvestris (Table S1).

280 For Sanger sequencing of $C O 1, \operatorname{Trp} B$ and $C y t B$, we used a total of 84 samples

281 belonging to eight aphid species (D. plantaginea, Dysaphis sp., Aphis citricola van der Goot,

282 Aphis pomi de Geer, and Aphis spiraecola Patch, Melanaphis pyraria Passerini, Myzus

283 persicae Sulzer, Rhopalosiphum insertum Walker) sampled on five host plant species ( $M$.

284 domestica, M. sylvestris, Sorbus aucuparia, Prunus persica, Pyrus communis). The species

285 were chosen to represent the aphid genus known to be closely related to the rosy apple aphid

286 (Choi et al., 2018). One to three individuals from each of the geographic sites listed above

287 and in Table S1 were sampled, for a total of 67 samples for D. plantaginea. The 17 additional

288 samples from seven other aphid species (one to two samples per aphid species) were

289 collected on the cultivated apple and other fruit tree species (Table S1).

$291 \quad$ PCR and Sanger sequencing 
292 We amplified the coding regions from the aphid mitochondrial cytochrome c oxidase subunit

293 I (CO1) gene and the cytochrome B ( $C y t B)$ gene. Fragments were amplified following the

294 protocol reported in Popkin et al. (2017) with some modifications (Table S2). The final PCR

295 volume was $30 \mu \mathrm{L}$, containing Buffer (1X), $\mathrm{MgCl}_{2}(1.5 \mathrm{mM})$, dNTP $(0.1 \mathrm{mM})$, Forward and

296 Reverse primers $(0.7 \mu \mathrm{M}), 5 \mu \mathrm{L}$ of Taq polymerase (1 U), and $5 \mu \mathrm{L}$ of DNA (1/10 dilution).

297 Amplification products were visualized on an agarose gel 1.5\% stained with ethidium

298 bromide under ultraviolet light. We prepared four 96-well plates with $15 \mu \mathrm{L}$ of PCR products

299 and a negative control. Plates were sent to Eurofins Genomics France SAS for sequencing.

300 Chromatograms were inspected and corrected with CodonCode Aligner version 8.0.1

301 (www.codoncode.com). Alignment, evaluation of all coding genes for frameshifts and

302 elimination of pseudogenes were performed with MEGA version 7.0.26 (Kumar, Stecher, \&

303 Tamura, 2016). The neutral evolution of each gene, and thus its suitability for phylogenetic

304 and population genetic analyses, was assessed with the McDonald and Kreitman test (Egea,

305 Casillas, \& Barbadilla, 2008; McDonald \& Kreitman, 1991) (Table S3). Two samples of

306 Brachycaudus helichrysi Kaltenbach, a pest of Prunus, for which sequences of CO1 (NCBI

307 sequence identifiers: KX381827.1, KX381828.1), CytB (KX381989.1, KX381990.1), and

$308 \operatorname{TrpB}(\mathrm{KX} 382153.1, \mathrm{KX} 38215.1)$ were available (Popkin et al., 2017), were used as outgroup.

309 Sequences were concatenated, resulting in a data matrix of 86 concatenated sequences.

\section{Phylogenetic tree and taxonomic assignation}

312 We checked the taxonomic assignation of the samples used in this study by running a

313 phylogenetic analyses including $D$. plantaginea and other aphid species found on fruit trees

314 with a Bayesian approach implemented in MrBayes v3.2.7 (Huelsenbeck \& Ronquist, 2001),

315 using the GTR "Generalized time-reversible" mutational model. The two M. pyraria

316 individuals were used as an external group. We chose the default parameters (unlink statefreq 
$317=($ all $)$ revmat $=($ all $)$ shape $=($ all $) ;$ prset applyto $=($ all $)$ ratepr $=$ variable $;$ mcmcp ngen $=$

3181000000 nruns $=2$ nchains $=4$ samplefreq $=1000$ printfreq $=1000)$. Inferred trees were

319 visualized with FigTree v1.4 (http://tree.bio.ed.ac.uk/software/figtree/).

\section{$321 \quad$ SSR genotyping}

322 We used 30 SSR markers, including one that was previously used for D. plantaginea

323 (Guillemaud et al., 2011), and 29 that were newly developed from the sequencing of a low

324 coverage genome (see details of the protocol in supplementary material Texts S2 and S3). We

325 tested the neutrality of the 29 SSR markers using the Ewens-Watterson neutrality test

326 ((Watterson, 1978); Text S3 and Table S4). Each SSR was amplified separately by PCR.

327 PCR was performed in a final volume of $20 \mu \mathrm{L}(0.2 \mu \mathrm{M}$ of each forward and reverse primer,

328 with the forward primer labeled with a fluorescent dye, $0.2 \mu \mathrm{M}$ of dNTPs, between 1 and 1.5

$329 \mathrm{mM}$ of $\mathrm{MgCl}_{2}, 1 \mathrm{X}$ Buffer (5X), $2 \mu \mathrm{L}$ of a homemade Taq, $5 \mu \mathrm{L}$ of DNA (1/30 dilution) and

330 sterile $\mathrm{H}_{2} \mathrm{O}$ to reach the final volume). We used the following PCR program: $94^{\circ} \mathrm{C}$ for 5

331 minutes, followed by 35 cycles of 30 s at $94^{\circ} \mathrm{C}, 30$ s at 60 to $65^{\circ} \mathrm{C}$ and $45 \mathrm{~s}$ at $72^{\circ} \mathrm{C}$, then 5

332 minutes at $72^{\circ} \mathrm{C}$ and finally 10 minutes at $4^{\circ} \mathrm{C}$. In the PCR program, the annealing

333 temperature varied between $55^{\circ} \mathrm{C}$ and $65^{\circ} \mathrm{C}$. Annealing temperatures for each SSR marker are

334 detailed in Supplementary Material Table S5. PCR products were then pooled according to

335 the four multiplexes described in Table S5.

336 SSR genotyping was performed at the Gentyane platform (INRAE, Clermont-Ferrand,

337 France). Alleles of each SSR marker were identified, and their size scored with Genemapper

338 v.4.0 (Applied Biosystems TM, Foster City, USA) by two people independently. In case of

339 discrepancy, the electropherogram was triple checked for a final decision. Allele scoring

340 resulting from Genemapper was then processed with the Autobin Excel Macro

341 (https://www6.bordeaux-aquitaine.inra.fr/biogeco eng/Scientific-Production/Computer- 
342 software/Autobin). We retained only multilocus genotypes with less than $30 \%$ missing data

343 and containing less than 5\% of null alleles. Null alleles were detected with GENEPOP v4.7

344 (Rousset, 2008).

346 Clonal population structure

347 Each individual was classified according to its multilocus genotype $(M L G)$ with GenoDive

$3482.0 \mathrm{~b} 23$ ((Meirmans \& Van Tienderen, 2004), Table S1). We used the stepwise mutation

349 model with a threshold of 0 and the corrected Nei's diversity index as a statistic to test clonal

350 population structure. To reduce the influence of clonal copies produced by asexual 351 reproduction on the Hardy-Weinberg equilibrium, allele frequency and genetic 352 differentiation estimates, the dataset was pruned to include only one copy of each $M L G$ for 353 further analyses.

\section{Population genetics descriptive statistics}

356 Observed and expected heterozygosity $\left(H_{O}\right.$ and $\left.H_{E}\right)$ and inbreeding coefficient $\left(F_{I S}\right)$ were 357 calculated with GENEPOP v4.7 (Rousset, 2008) from the SSR dataset for each SSR marker, 358 each site (i.e., geographic location/orchard) and each population (i.e., clusters inferred with 359 the STRUCTURE software, to comprise individuals with a membership coefficient of at least $36062.5 \%$ to the given cluster, see results). The $62.5 \%$ cut-off was chosen based on the

361 distribution of individual membership coefficients across the clusters detected for the most

362 likely $K$ value (see results). Pairwise genetic differentiation $\left(F_{S T}\right)$ between sites and between 363 populations was also calculated with GENEPOP (Rousset, 2008). Only sites with at least five 364 successfully genotyped samples were included for the site-specific computations. Allelic 365 richness and private allelic richness for each site and each population were calculated with 366 ADZE (Szpiech, Jakobsson, \& Rosenberg, 2008) using a sample size corresponding to the 
367 smallest number of observations per site or population, multiplied by two chromosomes (e.g.,

368 a sample size of 20 represents ten individuals x two chromosomes).

369 We also estimated Nei’s nucleotide diversity index $\pi$ (Nei, 1987), Watterson's index $\theta$

370 (Watterson, 1975), haplotype diversity, Tajima's $D$ (Tajima, 1989) and Fu's Fs (Fu, 1997)

371 with DNAsp (Rozas, Sànchez-DelBarrio, Messeguer, \& Rozas, 2003) using the concatenated

372 three-marker dataset (i.e., $C O 1, \operatorname{TrpB}$ and $C y t B$ ) for each population (i.e., cluster inferred

373 with STRUCTURE including individuals with membership coefficient $>62.5 \%$ to this

374 cluster, see results).

376 Detecting recent bottlenecks during population range expansion

377 We tested whether a bottleneck occurred during the range expansion of each population with

378 the method implemented in BOTTLENECK (Cornuet \& Luikart, 1996; Piry, Luikart, \&

379 Cornuet, 1999). Inferences regarding historical changes in population size are based on the

380 assumption that the expected heterozygosity estimated from allele frequencies decreases

381 faster than the expected heterozygosity estimated under a given mutation model at mutation-

382 drift equilibrium in populations that have experienced a recent reduction in size. The tests

383 were performed under the stepwise-mutation model (SMM) and a two-phase model (TPM)

384 allowing for $30 \%$ multi-step changes.

Spatial distribution of allelic richness and observed heterozygosity

387 Spatial patterns of allelic richness and observed heterozygosity were visualized by mapping

388 the variation in allelic richness and observed heterozygosity at 48 sites in total (i.e., sites with

389 at least five individuals) with the geometry-based inverse distance weighted interpolation in

390 QGIS (Quantum GIS, GRASS, SAGA GIS). The correlation between genetic variability $\left(H_{O}\right)$

391 and latitude, and between $H_{O}$ and longitude, was tested using a linear model. 


\section{Population subdivision}

394 We inferred the finest population structure by comparing the results obtained with three 395 population genetic tools: STRUCTURE 2.3.2 (Pritchard, Stephens, \& Donnelly, 2000), TESS

396 2.3.1 (Chen, Durand, Forbes, \& François, 2007), and a discriminant analysis of principal 397 components (DAPC) (Jombart, Devillard, \& Balloux, 2010). STRUCTURE is based on the 398 use of Markov chain Monte Carlo (MCMC) simulations to infer the assignment of genotypes 399 to $K$ distinct clusters. In addition to this, TESS also considers a spatial component, so that 400 genotypes from sites that are geographically closer to each other are considered more likely 401 to be in the same cluster. For both STRUCTURE and TESS, ten independent analyses were 402 carried out for each value of $K(1 \leq K \leq 10$ and $2 \leq K \leq 10$, respectively) with 500,000 403 MCMC iterations after a burn-in of 50,000 steps. STRUCTURE and TESS outputs were 404 processed with CLUMPP 1.1 .2 (Jakobsson \& Rosenberg, 2007) to identify potentially 405 distinct modes (i.e., clustering solutions) in replicated runs (10) for each $K$. We also assessed 406 the population subdivision with DAPC with the R package 'adegenet' (Jombart \& Collins, 407 2015), which does not rely on any assumption about the underlying population genetics 408 model, in particular concerning Hardy-Weinberg equilibrium or linkage equilibrium. The 409 number of genetic clusters was investigated with the find.cluster function (Jombart \& Collins, 410 2015; Ripley \& Ripley, 2001), which runs successive K-means for clustering. The automatic 411 cluster selection procedure 'diffNgroup' was used with n.iter set to $10^{6}$ and $n$.start set to $10^{3}$. 412 The ordination analysis (DAPC) was performed using the dapc function. The statistically 413 optimal number of principal components was assessed using the optim.a.score function. 414 Assessment of the samples assigned to a genetic cluster was performed using the compoplot 415 function. 
418 Regnaut, \& Goudet, 2005). For TESS, we used the rate of change of the deviation index

419 criterion $(D I C)$ to determine the amount of additional information explained by increasing $K$.

420 For DAPC, we looked at the BIC obtained with the adegenet package to estimate the optimal

$421 K$ value. However, the $K$ identified with the $D I C, B I C$ and $\Delta K$ statistics does often not 422 correspond to the finest biologically relevant population structure (Cornille et al., 2015;

423 Kalinowski, 2011; Puechmaille, 2016). We therefore visualized the bar plots with Pophelper 424 (Francis, 2016) and choose the $K$ value for which all clusters had well assigned individuals 425 while no further well-delimited and biogeographically relevant clusters could be identified 426 for higher $K$ values. For further analyses, we considered an individual to be assigned to a 427 cluster when its membership coefficient was $\geq 62.5 \%$ to this cluster (see results below).

428 The spatial pattern of genetic structure was visualized by mapping the mean 429 membership coefficients for each site, as inferred from each of the tree population genetics 430 structure analyses, with QGIS 3.12 'Las Palmas' (https://qgis.org). We further explored 431 relationships among populations with a principal component analysis (PCA, dudi.pca, ade4 R 432 package (Dray \& Dufour, 2007)).

\section{Isolation-by-distance}

436 We tested whether there was a significant isolation-by-distance (IBD) pattern. A Mantel test 437 with 10,000 random permutations was performed between the individual coefficient of 438 relatedness $F_{i j}$ (Loiselle, Sork, Nason, \& Graham, 1995) and the matrix of the natural 439 logarithm of geographic distance. We also performed a correlation between $F_{S T} /\left(1-F_{S T}\right)$ and 440 the natural algorithm of geographic distance. These analyses were performed using SPAGeDI 
4411.3 (Hardy \& Vekemans, 2002) separately for each D. plantaginea population (i.e., cluster

442 containing individuals with a membership coefficient > 0.625) identified with TESS,

443 STRUCTURE, and DAPC.

\section{Demographic and divergence history using ABC-RF}

446 We used approximate Bayesian computation to investigate whether the spatial patterns of 447 genetic clustering, diversity and differentiation observed in D. plantaginea resulted from the 448 occurrence of gene flow among populations during colonization. We also attempted to infer 449 the relative sequence of colonization events in each population. We used the newly developed 450 ABC method based on a machine learning tool named "random forest" (ABC-RF) to perform 451 model selection and parameter estimations (Estoup et al., 2018; Pudlo et al., 2016; Raynal et 452 al., 2019). In brief, this method creates a "forest" of bootstrapped decision trees to classify 453 scenarios based on the summary statistics of the datasets. Some simulations are not used to 454 build the trees and can thus be used to cross-validate the analysis by computing a "prior error 455 rate". This approach allows the comparison of complex demographic models (Pudlo et al., 456 2016) by comparing groups of scenarios with a specific type of evolutionary event with other 457 groups with different types of evolutionary events (instead of considering all scenarios 458 separately) (Estoup et al., 2018).

459 We used a nested ABC approach with two key steps. First, we inferred the divergence 460 and demographic history of the rosy apple aphid in Europe (step 1). Then, we tested the 461 divergence and demographic history of the rosy apple aphid outside of Europe (step 2). Each 462 ABC step compared different sequences of colonization events, with and without 463 bidirectional gene flow among populations (Figure S2). This two-step nested approach avoids 464 the need to compare models that are too complex, which would require the simulation of too 465 many populations and parameters, and is more powerful than testing all scenarios 
466 individually to determine the main evolutionary events that characterize demographic history

467 and divergence (Estoup et al., 2018). Populations were defined as the clusters detected with

468 STRUCTURE (see results), removing putative hybrid individuals (i.e., individuals with a

469 membership coefficient $<62.5$ to any given cluster). The model parameters used were: the

470 divergence time between $X$ and $Y$ populations $\left(T_{X-Y}\right)$, the effective population size of

471 population $X\left(N_{E-X}\right)$, the migration rate per generation between $X$ and $Y$ populations $\left(m_{X-Y}\right)$.

472 Prior values for divergence time were drawn for the log-uniform distribution bounded

473 between the distributions used in the approximate Bayesian computations, and are given in 474 Table S6.

475 For all models, identical SSR datasets were simulated for 29 out of the 30 markers 476 that had perfect repeats (we excluded the L4 marker because it did not have perfect repeats, 477 Tables S4 and S5), increasing confidence in the simulated model. We preliminarily checked 478 that the population structure inferred with 29 SSR markers did not differ significantly from 479 the inferences obtained with 30 SSR markers (data not shown). We assumed a generalized 480 stepwise model of SSR evolution. Mutation rates were allowed to vary across loci, with 481 locus-specific mutation rates drawn from a gamma distribution $(\alpha, \alpha / \mu)$ where $\mu$ is the 482 mutation rate per generation and $\alpha$ is a shape parameter. We assumed a log-uniform prior 483 distribution for $\mu(1 \mathrm{e}-4,1 \mathrm{e}-3)$ and a uniform distribution for $\alpha(1.30)$.

484 We used ABCtoolbox (Wegmann, Leuenberger, Neuenschwander, \& Excoffier, 2010) 485 with fastsimcoal 2.5 (Excoffier \& Foll, 2011) to simulate datasets, using model parameters 486 drawn from prior distributions (Table S6). We performed 10,000 simulations per scenario. 487 For each simulation, we calculated six summary statistics per population with arlsumstats $\mathrm{v}$ 4883.5 (Excoffier and Lischer 2010): $H$, the mean heterozygosity across loci, $s d(H)$, the standard 489 deviation of the heterozygosity across loci, $G W$, the mean Garza-Williamson statistic across 490 loci (Garza and Williamson, 2001), $s d(G W)$, the standard deviation of the mean Garza- 
491 Williamson statistic over populations, $N G W$, the mean modified Garza-Williamson statistic

492 over loci, $s d(N G W)$, the standard deviation of the mean modified Garza-Williamson statistic

493 over populations. We also computed pairwise $F_{S T}$ (Weir and Cockerham, 1984) and genetic

494 distances $(\delta \mu)^{2}$ (Goldstein et al., 1995) between pairs of populations.

495 We used the abcrf v.1.7.0 R statistical package (Pudlo et al., 2016) to carry out the

496 ABC-RF analysis. This analysis provides a classification vote that represents the number of

497 times a scenario is selected as the best one among $\mathrm{n}$ trees in the constructed random forest.

498 For each ABC step, we selected the scenario, or the group of scenarios, with the highest

499 number of classification votes as the best scenario, or best group of scenarios, among a total

500 of 500 classification trees (Breiman, 2001). We computed the posterior probabilities and prior

501 error rates (i.e., the probability of choosing a wrong group of scenarios when drawing model

502 index and parameter values from the priors of the best scenario) over 10 replicate analyses

503 (Estoup et al., 2018) for each ABC step. We also checked visually that the simulated models

504 were compatible with the observed dataset by projecting the simulated and the observed

505 datasets onto the two first linear discriminant analysis (LDA) axes (Pudlo et al., 2016), and

506 checking that the observed dataset fell within the clouds of simulated datasets. We then

507 calculated parameter inferences using the final selected model following the three-round

508 ABC procedure. Note that the ABC-RF approach includes the model checking step that was

509 performed a posteriori in previous ABC methods.

511 Characterization of the symbiotic bacterial community using the 16S rRNA bacterial

512 gene

513

514 In order to investigate symbiont diversity, we amplified a 251 bp portion of the V4 region of

515 the 16S rRNA gene (Mizrahi-Man, Davenport, \& Gilad, 2013) and used targeted sequencing

516 of indexed bacterial fragments on a MiSeq (Illumina) platform (Kozich, Westcott, Baxter, 
517 Highlander, \& Schloss, 2013) following the protocol described in (Jousselin et al., 2016). We

518 used 178 aphid DNA extracts (Table S1), comprising 175 D. plantaginea individuals and

519 three M. pyraria individuals, which represent the range of our sampling (Table S1). We also

520 added eight randomly chosen samples that did not undergo the two extra chemical washes

521 (see Material and methods, and Table S1). Each sample was amplified twice along with

522 negative controls (DNA extraction and PCR controls). PCR replicates were conducted on

523 distinct 96-well microplates. We obtained a total of 390 PCR products (186 DNA extracts, by

5242 for PCR duplicates, plus PCR controls), which were pooled and then separated by gel

525 electrophoresis. Bands based on the expected size of the PCR products were excised from the

526 gel, purified with a PCR clean-up and gel extraction kit (Macherey-Nagel), and quantified

527 with the Kapa Library Quantification Kit (Kapa Biosystems). Paired-end sequencing of the

528 DNA pool was carried out on a MISEQ (Illumina) FLOWCELL with a 500-cycle Reagent

529 Kit v2 (Illumina).

530 We first applied sequence filtering criteria following Illumina's quality control

531 procedure. We then used a pre-processing script from (Sow et al., 2019) to merge paired

532 sequences into contigs with FLASH V.1.2.11 (Magoč \& Salzberg, 2011) and trim primers

533 with CUTADAPT v.1.9.1 (Martin, 2011). We then used the FROGS pipeline (Escudié et al.,

534 2018) to generate an abundance table of symbiont lineages across samples. In brief, we first

535 filtered out sequences $>261$ bp and $<241$ bp with FROGS, then we clustered variants into

536 operational taxonomic units (OTUs) with SWARM (Mahé, Rognes, Quince, Vargas, \&

537 Dunthorn, 2014) using a maximum aggregation distance of three. We identified and removed

538 chimeric variants with VSEARCH (Rognes, Flouri, Nichols, Quince, \& Mahé, 2016). We

539 only kept OTUs that were present in both PCR replicates of the same sample and then

540 merged the number of reads for each OTU for each aphid sample. 
541 Taxonomic assignment of OTUs was carried out using RDPtools and Blastn

542 (Altschul, Gish, Miller, Myers, \& Lipman, 1990) against the Silva138-16s database

543 (https://www.arb-silva.de) as implemented in FROGS. From the abundance table of OTUs

544 across samples, we transformed read numbers per aphid sample into frequencies

545 (percentages); sequences accounting for $<0.5 \%$ of all the reads for a given sample were

546 excluded following Jousselin et al. (2016). All filters resulted in excluding reads found in low

547 abundance that could represent sequencing errors and which were also often found in the

548 negative controls.

$550 \quad$ Results

551

552 Taxonomic status of aphid samples

553 The Bayesian phylogenetic tree built with the 86 sequences representing nine aphid species

554 resulted in a polytomy for the 67 D. plantaginea samples from Europe, Morocco, and the

555 USA, showing very little sequence variation at the intraspecific level (low bootstrap values <

556 0.6, Figure S3a). We therefore kept only two representatives out of the $67 \mathrm{D}$. plantaginea

557 individuals in subsequent phylogenetic analyses. Bayesian analysis of this pruned dataset

558 comprising 19 individuals representing nine aphid species confirmed known phylogenetic

559 relationships in Aphidinae (Choi et al., 2018), Figure S3b). The species A. pomi, A. citricola

560 and $A$. spiraecola were grouped in the same clade, the three species appearing polyphyletic

561 (Figure S3b). Dysaphis plantaginea appeared closely related to other members of the

562 Macrosiphini tribe (B. helichrysi and $M$. persicae). Interestingly, the samples from Iran

563 clustered apart from the D. plantaginea clade, the former belonging to the Dysaphis sp.

564 species. This result suggests that the two $D$. sp. Iranian samples belong to a yet unidentified

565 species, or resulted from strong intraspecific differentiation. Those two samples were not 
566 included in the population genetics analyses using SSR, as we only had two representants

567 from this Caucasian region (Table S1).

568

\section{Clone detection}

570 Overall, the proportion of unique genotypes was variable among sites. We found 582 unique 571 genotypes, including 29 unique genotypes that were represented by 85 clones. Clones 572 therefore represented 85 individuals (12.7\% of the total dataset, Table S7), mainly coming 573 from Belgium, (86\% of the clones, eight sites; mean proportion of unique genotypes (mean $574 \mathrm{G} / \mathrm{N})=0.36 \pm 0.2)$, Bulgaria $(6 \%$, one site, $\mathrm{G} / \mathrm{N}=0.67)$, France $(5 \%$, three sites, mean $G / N=$ $5750.87 \pm 0.05)$, the USA ( $1 \%$, one site; $G / N=0.93)$, Spain, $(1 \%$, one site; $G / N=0.91)$ and 576 from the lab-reared aphids $(1 \%, G / N=0.09)$. We only kept the 582 unique genotypes for the 577 analyses presented below.

\section{Spatial distribution of allelic variation}

580 The map of allelic richness (Figure 1a) showed that genetic diversity decreased along a north-

581 east to south-west gradient, with the highest allelic richness found in northeastern Europe and 582 the lowest in Morocco and the USA, except for Belgium that showed a lower level of genetic 583 diversity. We found a significant correlation between allelic richness and longitude $(r=$ $5840.2294, P$-value $=0.000573)$, and between allelic richness and latitude $(r=0.2684, P$-value $=$ 585 0.000162). The map of observed heterozygosity (Figure 1b) confirmed that genetic diversity 586 decreased along a north-east to south-west gradient, with the highest allelic richness in 587 Denmark and the lowest in Morocco. We found a significant correlation between observed 588 heterozygosity and longitude $(r=0.1731$, P-value $=0.00327)$, and between observed 589 heterozygosity and latitude $(r=0.4998, P$-value $=1.95 \mathrm{e}-08)$. 
591 Population structure and subdivision

592 The spatial genetic structures of D. plantaginea inferred with TESS, DAPC and

593 STRUCTURE, and the respective DIC, BIC, and $\triangle K$, are shown in Figure 2 and 594 supplementary material Figures S4 to S9. For each $K$ value, CLUMPP analyses produced 595 highly similar clustering patterns among the 10 repetitions (average $G^{\prime}>95 \%$ ). We therefore 596 only present here the major modes.

597 With TESS, increasing $K$ above 3 did not reveal any additional cluster (Figure S4).

598 For $K=3$, TESS analyses revealed a clear partition between the Moroccan samples (blue), 599 and other samples (European and North American, orange). An additional cluster was 600 identified comprising only one Italian individual (yellow) (Figure 2a). With DAPC, 601 increasing $K$ above 4 did not reveal well-delimited new clusters, i.e., the new clusters were 602 only individuals with multiple admixtures (Figure S5). For $K=4$, DAPC identified three 603 well-delimited clusters (Figure 2b): one in Eastern Europe (i.e., Bulgaria, Italy and Romania, 604 in yellow), one in Morocco (blue), one in the USA (orange), plus another cluster that 605 comprised the rest of the Western European (Spain, France, Belgium, the UK) and Danish 606 samples (pink). With STRUCTURE, increasing $K$ above 5 did not reveal additional clusters.

607 For $K=5$ (Figure 2c), samples were partitioned as follows: Morocco (blue), the USA 608 (orange), Spain (pink), Eastern Europe and Italy (green), and Western Europe and Denmark 609 (yellow).

610 We used the inferences from the STRUCTURE analysis in subsequent analyses 611 because it revealed the finest population genetic structure. Genotypes were then assigned to a 612 given population if their membership coefficient for that population exceeded 0.625 (Table 1

613 and Table S1). We chose this threshold based on the bimodal distribution of membership 614 coefficients inferred with STRUCTURE (Figure S10). A total of 175 individuals (30\% of the 
615 dataset) could not be assigned to any population and were not included in subsequent 616 analyses.

617 We further visualized and quantified the genetic differentiation among populations 618 with a principal component analysis (PCA, Figure 2d) and $F_{S T}$ estimates (Figure 2e), 619 respectively. Among all populations, $F_{S T}$ values were low but all significant (Figure 2e). 620 Pairwise genetic differentiation was the lowest between the European populations $\left(F_{S T}=\right.$ 6210.02, P-value $<0.0001$, Figure 2e); the Moroccan and US populations were the most 622 differentiated (Figure 2e). The PCA showed similar genetic relationships among the five 623 populations (Figure $2 \mathrm{~d}$ ).

\section{Genetic diversity, bottleneck and range expansion}

626 The mean expected heterozygosity was relatively high (average $=0.74$ with values ranging 627 from 0.55 to 0.75 , Table $S 8$ ). The mean $F_{S T}$ across all loci was low (mean $F_{S T}=0.08$, range: $6280.006-0.5)$ but significant for all pairs of sites $(P$-value $<0.001$, Figure S11).

Allelic richness and private allelic richness were significantly different among the five 630 populations, except between the American and Moroccan populations for allelic richness, and 631 among the Spanish, Moroccan and Eastern European populations for private allelic richness 632 (Table S9). The North American and Moroccan populations showed significantly lower 633 levels of allelic richness and private allelic diversity compared to the European populations 634 (i.e., Spanish, Eastern and Western European populations; Tables 1 and S9). In Europe, the 635 Eastern European/Italian population had the highest level of allelic richness and private 636 allelic diversity, followed by the Western European/Danish population, and lastly the Spanish 637 population.

638 We also tested whether a strong and recent bottleneck occurred for each population. 639 BOTTLENECK analyses showed no significant deviation from the mutation-drift 
640 equilibrium in any of the populations (Table S10). Tajima's $D$ and Fu's $F_{S}$ statistics did not

641 reveal any signature of demographic range expansion either (Table 1).

\section{Isolation-by-Distance (IBD)}

644 A significant but weak IBD pattern was observed $(r=0.057, P$-value $\leq 0.05)$ for the rosy apple 645 aphid (Figure S11). The $S p$ statistic can be used to quantify spatial structure and is useful for 646 comparing populations and/or species. Low $S p$ values are associated with greater dispersal 647 capacities and/or effective population sizes. Here, $S p$ values were extremely low (close to 0 ) 648 and were only significant for the Moroccan and the Western European/Danish populations

649 (Table 1). These results suggest that D. plantaginea has high dispersal capacities and/or large 650 effective population sizes.

\section{Inference of the divergence and demographic history of the rosy apple aphid}

653 First, we reconstructed the divergence and demographic history of the rosy apple aphid in 654 Europe (i.e., including only the Spanish, Eastern European/Italian and Western 655 European/Danish populations). We defined 12 scenarios assuming different divergence 656 histories of the Eastern European/Italian, Western European/Danish and Spanish populations 657 (Figure S2). The 12 scenarios were tested with and without gene flow among populations. 658 We therefore ended up comparing 24 scenarios. Classification votes from the first round were 659 the highest ten times out of ten for the group of scenarios that assumed gene flow among the 660 three populations (295 votes out of the 500 RF trees, posterior probability $P=0.61$, prior 661 error rate $=3.04 \%$, Table S12, Figure S12). Projection of the reference table datasets and the 662 observed dataset on a single axis showed that the observed data fell within the distribution of 663 the simulated summary statistics of the group of scenarios that assumed gene flow among the 664 three populations, suggesting this analysis had the power to discriminate between the two 
665 groups of scenarios and to identify the most likely scenario (Figure S12). The second round

666 of $\mathrm{ABC}$ inferences testing the sequence of colonization of the European populations requires

667 caution in interpretation as prior error rates were high and posterior probabilities low (Figure

668 S12 and Table S13).

669 We then investigated the colonization history of the rosy apple aphid outside of

670 Europe, i.e., of the Moroccan and American populations. Given the lack of power to

671 discriminate between different scenarios of colonization sequence of the rosy apple aphid in

672 Europe, and the weak genetic differentation among the three European populations (mean $F_{S T}$

$673=0.02$, Figure 2e), we merged the three European populations into a single European

674 population $(N=316)$ for this analysis. We then defined six scenarios of sequence of

675 colonization starting either from Europe or Morocco (Figure S2). We excluded the hypothesis

676 that the rosy apple aphid originated in North America. Indeed, historical records show that

677 the introduction of the rosy apple aphid was very recent in America (ca. 1890s) (Foottit et al.,

678 2006). Furthermore, the American population had the lowest levels of private allelic diversity

679 and allelic richness, and the American samples clustered with the European samples in the

680 DAPC and TESS analyses. For each of the six scenarios, five scenarios of gene flow among

681 populations were tested: no gene flow, gene flow among all populations and gene flow

682 between each population pair (i.e., Europe/Morocco, Europe/the USA, and Morocco/the

683 USA). We assumed these specific models of gene flow among specific pairs of populations

684 for the ABC-RF as we observed variable admixtures among populations (Figure 3c). In total,

68530 scenarios were compared (six colonization sequences x five gene flow modes, Figure S2).

686 ABC-RF analyses showed relatively high support for scenarios assuming gene flow (ABC-

687 RF round 1,10 out of the 10 replicates for the groups of scenarios assuming gene flow, 337

688 votes out of the 500 RF trees, posterior probability $P=0.65$, prior error rate $=6.55 \%$, Table

689 S14, Figure S13). Projection of the reference table datasets and the observed dataset on a 
690 single axis showed that the observed data fell within the distribution of the simulated

691 summary statistics of the group assuming gene flow, suggesting this analysis infer the

692 occurrence of gene flow (Figure S13). However, although the observed dataset fell within the

693 distribution of simulated summary statistics (Figure S13), we lacked of power to infer the

694 sequence of colonization of the rosy apple aphid outside of Europe (i.e., posterior probability

$695 P=0.65$, and high prior error rate $=73.82 \%$, Table S15).

696 Altogether, ABC-RF inferences supported the occurrence of gene flow during the 697 colonization history of $D$. plantaginea. However, ABC-RF did not allow to determine the 698 sequence of colonization of Europe, America and Morroco by the rosy apple aphid.

\section{S rRNA amplicon sequencing}

701 After sequence filtering using the FROGS pipeline, high-throughput sequencing of $16 \mathrm{~S}$

702 rRNA bacterial genes from 186 aphids resulted in $5.7 \mathrm{M}$ sequencing reads with an average of

70330,800 reads per aphid sample. We found an extremely low diversity of bacterial symbionts

704 in D. plantaginea. The 5.7 M sequencing reads were clustered into 18 OTUs (Figure S15,

705 Table S1). Seven OTUs were assigned to B. aphidicola and made up $97.8 \%$ of the sequencing

706 reads (92\% of the reads were assigned to a single $B$. aphidicola OTU, which was found

707 associated with all D. plantaginea individuals, the remaining B. aphidicola OTUs were found

708 associated with "outgroups"). The remaining reads were mainly assigned to two known aphid

709 endosymbionts, Serratia symbiotica and Regiella insecticola, which were found in eight and

710 three aphid specimens, respectively. The three aphids hosting Regiella belonged to a

711 population of $M$. pyraria collected in Switzerland, while aphids hosting Serratia were found

712 in distantly related populations including D. plantaginea collected on $M$. domestica from

713 various apple orchards in France, and in Iran on P. communis (Table S1). These results

714 highlighted the extremely limited diversity of symbionts across a large geographical scale. 


\section{Discussion}

717 We investigated the demographic history of a major fruit tree pest, the rosy apple aphid, in

718 the regions where it impacts the most cultivated apple orchards (i.e., Europe, North Africa

719 and North America). Using multiple lines of evidence, we showed that the colonization of

720 Europe by the rosy apple aphid is likely recent, did not involve strong bottlenecks, and did

721 involve gene flow between and within populations. The high level of gene flow among

722 populations and within populations was supported by the weak spatial genetic structure

723 observed across Europe, and coalescent-based simulation combined with ABC-RF. We also

724 found that $D$. plantaginea rarely hosts endosymbiotic bacteria other than their primary

725 symbiont, Buchnera aphidicola. Our results provide further understanding of the evolutionary

726 processes at play during pest range expansion. We discussed the impacts of our results for

727 pest control programs.

728

729 Colonization of apple trees by the rosy apple aphid is recent, and did not involve drastic

730 bottlenecks

731 After removing clones from our analyses, we detected five main populations of the rosy apple

732 aphid: three in Europe, one in Morocco and one in the USA. The genetic diversity for each

733 population was within the same range as other aphid species such as B. helichrysi (Popkin et

734 al., 2017), Eriosoma lanigerum (Zhou et al., 2015) and M. persicae nicotianae

735 (Zepeda $\square$ Paulo et al., 2010). Our findings support that one round of sexual reproduction per

736 year in D. plantaginea is sufficient to generate genetic diversity. However, genetic diversity

737 (private alleles and allelic richness) in D. plantaginea was higher in Europe, but lower in the

738 USA and Morocco. More generally, patterns of genetic structure and diversity suggest 
739 different demographic histories for the European, Moroccan and American populations of $D$. 740 plantaginea.

741 Individuals from the European populations had partial membership to the multiple 742 clusters, with similar membership coefficients for most individuals. This pattern of high 743 admixture along a spatial transect might reflect a continuous gradation in allele frequencies 744 (i.e., a cline) across regions that cannot be detected by the methods used in this study. Indeed, 745 a major limitation of all clustering approaches is the risk of inferring artefactual discrete 746 groups in populations where genetic diversity is distributed continuously. DAPC and 747 STRUCTURE are not immune to this bias and may erroneously identify clusters within a 748 cline (Jombart et al., 2010). TESS is more sensitive to allelic gradient; this program includes 749 a decay of the correlation between membership coefficients and distance within clusters 750 (Chen et al., 2007). In the presence of clines and with evenly distributed sampling, TESS may 751 detect fewer clusters than STRUCTURE (Durand, Chen, \& François, 2009). The larger 752 admixed clusters found with DAPC and STRUCTURE may therefore reflect a cline of allele 753 frequency across Europe for the rosy apple aphid. Allele frequency clines can result from 754 admixture between genetically distinct populations (Currat \& Excoffier, 2005; Menozzi, 755 Piazza, \& Cavalli-Sforza, 1978) and/or from subsequent founder events during range 756 expansion (Barbujani, Sokal, and Oden 1995; Fix 1997; Currat and Excoffier 2005). Genetic 757 diversity is also expected to decrease along the expanding range (François, Blum, Jakobsson, 758 \& Rosenberg, 2008; Prugnolle, Manica, \& Balloux, 2005). Founder events associated with a 759 recent range expansion may have resulted in the decreasing east-west gradient of genetic 760 diversity and the large number of admixed individuals observed in Europe. It is therefore 761 possible that the European populations of the rosy apple aphid underwent a recent expansion.

762 Note that we did not detect any signature of range expansion with the three-markers dataset $763(C O 1, c y t B$ and $\operatorname{trp} B)$. This lack of signature of range expansion may be due to limited 
764 number of samples used in our test (at least for the Moroccan and American populations), but

765 also that the range expansion is so recent that we cannot catch its footprint with our sequence

766 markers. Several preliminary ABC-RF tests of range expansion of the rosy apple aphid in

767 Europe that failed (i.e., very low posterior probabilities and prior error rates, data not shown)

768 suggest that the second hypothesis is possible.

769 The Moroccan and North American populations displayed a different pattern of 770 population differentiation and diversity compared with the European populations, suggesting

771 an even more recent colonization history. The two populations were well circumscribed, and

772 had the highest level of genetic differentiation from the European populations, the lowest

773 genetic diversity and the lowest number of private alleles. In the TESS analysis, the

774 American samples did not cluster separately from the European samples, and in the DAPC

775 analysis, samples from America and Western Europe clustered together, suggesting that the

776 American population originated recently from Europe. This is in agreement with the earliest

777 record of D. plantaginea in the Eastern US dating back to 1890 (Foottit et al., 2006). Since

778 then, there have probably been multiple introductions into the USA that prevented genetic

779 differentiation from Europe. Similar scenarios have been described for the tobacco aphid,

780 which was introduced into America from different European pools (Zepeda $\square$ Paulo et al.,

781 2010), and the leaf-curl plum aphid B. helichrysi (Piffaretti et al., 2013) for which population

782 genetic tools showed very little differentiation between European and North American

783 populations. As for the Moroccan population, we lacked the power to infer its origin with the

784 ABC-RF method. However, the significantly lower genetic diversity and number of private

785 alleles in this population compared with that of Europe, the high level of admixture and the

786 close genetic relationship with the Spanish population, suggest that the Moroccan population

787 resulted from a recent colonization event from Southern Europe. Nevertheless, the history of

788 the rosy apple aphid in North Africa deserves further investigation requiring additional 
789 sampling in this region. Altogether, the significantly lower genetic diversity observed in the

790 Moroccan and American populations suggest that these originated recently through relaxed

791 founder events. Indeed, we did not find any evidence that these two populations underwent a

792 recent strong bottleneck despite having significantly lower diversity in both SSR and 793 sequence markers. Thus, the founder effect underlying the colonization of North America and

794 Morocco may involve genetic drift in small populations rather than severe bottlenecks at the

795 introduction event. Genetic diversity was also found to be higher in native populations within

796 their native range in the tobacco aphid (Zepeda-Paulo et al., 2010) and the Russian wheat

797 aphid (Zhou et al., 2015).

798 Altogether, a recent range expansion of the rosy apple aphid on its cultivated apple

799 host is a plausible explanation of the observed spatial genetic structure and diversity. Rapid

800 range expansion has also been described in the Russian wheat aphid (Zhang et al., 2014).

801 Unfortunately, the ABC-RF method was not powerful enough to disentangle the different

802 scenarios of colonization of the rosy apple aphid. The difficulty in elucidating the recent

803 colonization history of the rosy apple aphid using $\mathrm{ABC}$ is likely due to the weak genetic

804 differentiation among populations and to the occurrence of gene flow. However, the ABC-RF

805 method was powerful enough to identify the occurrence of gene flow within and outside

806 Europe.

807

808 Colonization with gene flow, likely driven by humans

809 We found that the expansion of the rosy apple aphid involved several populations with high

810 genetic diversity each, and inter- and intra- population gene flow across Europe, North

811 America and Morocco. ABC-RF analyses strongly support scenarios with bidirectional gene

812 flow among populations. The $S p$ parameter estimated within each population revealed large

813 extent of historical gene flow within population. We used the $S p$ parameter estimates to

814 compare the dispersal capacities of $D$. plantaginea with existing estimates in plants 
815 (Vekemans \& Hardy, 2004). The rosy apple aphid showed dispersal capacities equivalent to

816 or even higher than that of wind-dispersed trees. The rosy apple aphid can therefore spread

817 over kilometers, as suggested previously (Guillemaud et al., 2011), and as largely recognized

818 in aphids (Loxdale et al., 1993). However, despite its high dispersal capacities and the large

819 amount of gene flow among and within populations, we can still observe a weak, but

820 significant, spatial genetic structure across its distribution. This subtle observed spatial

821 genetic structure may be associated with human agricultural practices. The interchange of

822 apple materials (i.e., cultivars in form of scions and/or trees) is nowadays and, probably has

823 been historically, frequent and a potential way of moving the rosy apple aphid in form of

824 overwintering eggs among regions where apple is cultivated. This hypothesis agrees with a

825 differentiated population observed in Asturias (Northwestern Spain). In this region, apple

826 production is mainly used for cider-making and is based on local cider cultivars (Tardío,

827 Arnal, \& Lázaro, 2020). Since most of our samples from Spain are from Asturias, except the

828 Catalan samples that were clustering with the European ones, the exchange of apple material

829 within Asturias, and within other regions in Europe, may have been more intense, implying

830 higher risk of aphid movement within regions than between regions. Of course, this is not the

831 only explanation of the spatial genetic structure observed, physical barriers could also explain

832 the higher genetic differentiation of the Moroccan and American populations.

\section{Putative center(s) of origin of the rosy apple aphid}

835 The geographical origin of D. plantaginea remains unresolved. Our phylogenetic analyses

836 confirmed previous relationships between the rosy apple aphid and other aphids (Bašilova \&

837 Rakauskas, 2012; Rebijith et al., 2017). However, estimates of the divergence time of $D$.

838 plantaginea from closely related species is now required, with denser sampling of the

839 Dysaphis genus across several regions in Eurasia and molecular dating analyses. 
840 Genetic diversity estimates from SSR markers yet suggest that the source population

841 came from Eastern Europe, but it may also originate even further east in Central Asia where

842 its fruit tree host was originally domesticated (Cornille et al., 2014; Harris et al., 2002). Our

843 fail to collect D. plantaginea samples in this area, despite our attempts in China and

844 Kazakhstan, prevents us from testing this scenario. However note that while D. plantaginea

845 has been recorded in Central Asia according to several faunistic surveys (Kadyrbekov, 2002),

846 it is hard to find in these regions. Furthermore, a lack of records of this species in the Global

847 Biodiversity Information Facility (GBIF, 2020) also casts doubt as to whether D. plantaginea

848 is common in this area.

849 Alternatively, D. plantaginea may have originated in the Caucasus or Asia Minor, 850 maybe through a host jump from Pyrus to Malus. Dysaphis plantaginea, Dysaphis radicola,

851 Dysaphis devecta, Dysaphis brancoi, Dysaphis anthrisci, Dysaphis chaerophylli are Dysaphis

852 species reported to feed on the cultivated apple $M$. domestica as its primary host (Blommers

853 et al., 2004; Stekolshchikov, 2006), but many aphid species also feed on pears including,

854 Dysaphis reaumuri Mordvilko and Dysaphis pyri Boyer de Fonscolombe is Pyrus L.

855 (Barbagallo, Cocuzza, Cravedi, \& Komazaki, 2007). The Pyrus genus is known to have

856 diverged a long time ago from the genus Malus probably in the Caucasus (Celton et al., 2009;

857 Xiang et al., 2017). Therefore, the ancestral group from which D. plantaginea diverged might

858 have had a Pyrus species as host. Analysis of samples from these regions is required to test

859 this hypothesis.

\section{Low endosymbiont bacterial diversity associated with $D$. plantaginea}

862 Our results showed that bacterial diversity was strikingly low in D. plantaginea across

863 Europe, North America and Morocco. As expected, B. aphidicola was the predominant

864 bacterial species (97\% of our reads). However, at least nine secondary endosymbionts have 
865 been reported among aphid species (reviewed in Zytynska \& Weisser, 2016), including

866 Arsenophonus Gherma, Hamiltonella defensa Moran, Regiella insecticola, Rickettsia Da

867 Rocha-Lima, Rickettsiela Drobne, Serratia symbiotica, Spiroplasma Saglio and Wolbachia

868 Hertig \& Wolbach, and Fukatsuia. Here, we detected the presence of other bacteria only in a

869 few samples. A Serratia sp. was the only secondary symbiont identified and it was found in

870 only eight samples of D. plantaginea, collected on Pyrus communis in Iran, and in France and

871 Spain on $M$. domestica. A Regiella sp. was found in three samples from another aphid

872 species, M. pyraria collected on $M$. domestica. At least seven endosymbionts (H. defensa, $R$.

873 insecticola, Rickettsia sp., Rickettsiela sp., S. symbiotica, Spiroplasma sp. and Wolbachia sp.)

874 have been reported across a narrower spatial distribution in the model species Acyrthosiphon

875 pisum and several other well-studied aphid species (Zytynska \& Weisser, 2016). By contrast,

876 another study (Henry, Maiden, Ferrari, \& Godfray, 2015) found that neither D. plantaginea

877 nor other Dysaphis species hosted any secondary symbionts, although it relied on a small

878 number of individuals. This lack of endosymbiont bacterial diversity in D. plantaginea shows

879 that its likely fast expansion is not the result of an association with different mutualistic

880 endosymbionts.

881

\section{Concluding remarks}

883 This study demonstrated that the colonization of a major fruit tree aphid pest occurred

884 without strong bottleneck, maintaining high genetic diversity, and generated differentiated

885 populations exchanging gene flow, with an isolation by distance pattern. The high level of

886 within- and between- populations gene flow for the rosy apple aphid suggest that pesticide-

887 resistant genotypes or genotypes circumventing plant resistance may invade large areas very

888 rapidly after its emergence. Yet, the evidence of three differentiated populations in Europe,

889 possibly resulting from human-mediated scion exchanges impacting gene flow within and 
890 between populations, suggest that such a spread of resistant genotypes may be contained.

891 Besides, the evidence for no long-term demographic changes in the populations of $D$.

892 plantaginea in Europe, except for the Belgian populations, indicates that seasonal selective

893 pressures, such as insecticide application, have little impact on the genetic diversity of the

894 species. These results have implications in control and management of $D$. plantaginea, but

895 further studies are needed to fully understand how selective pressures have impacted $D$.

896 plantaginea adaptation. Finally, the origin of the rosy apple aphid is still unknown. Our

897 results suggest it may have originated in Eastern Europe, the Caucasus or Asia Minor.

898 However, the domestication of apple in this region remains unknown (Cornille et al., 2019,

899 2014; Spengler, 2019). Further investigations on the history of apple domestication and

900 additional sampling of D. plantaginea in the Caucasus or Asia Minor, as well as sampling

901 related aphid species, are required to better understand the origin of this major fruit tree pest.

902

903 Acknowledgments

904 This research was funded by the laboratoire d'Excellence Biodiversity Agrosystem Society

905 and Climate BASC (grant «Emergence POMPUCEDOM») and Systematic Research

906 funding, ATIP-Avenir program and the Institut Diversité Ecologie et Evolution du Vivant

907 (IDEEV). AR and TU were supported by a grant of the Romanian Ministry of Education and

908 Research, CCCDI - UEFISCDI, project number 384 PED-PN-III-P2-2.1-PED-2019-4924.

909 We thank the Plateforme de Génotypage GENTYANE INRAE UMR 1095 for assistance in

910 genotyping, and especially the platform leader Charles Poncet. We thank the informatics

911 team at the GQE-Le Moulon, in particular Adrien Falce, Benoit Johannet and Olivier

912 Langella. We are grateful to the INRAE MIGALE bioinformatics facility (MIGALE, INRAE,

913 2020. Migale bioinformatics Facility, doi: 10.15454/1.5572390655343293E12) for providing

914 help and/or computing and/or storage resources. 
916 Authors contributions. AC, EJ, PD, LJ conceived and designed the experiments; AC, EJ, PD,

917 LJ, MH, TG obtained funding; AC, AR, AA, TB, GA, FP, AH, SKJ, RA, SS, LS, EG, LT,

918 FG, KM, YK, ARom, TD, IZ, OS, RJM, AA, BEH, EJ, HZ, IB, MR, HT, CM, BB, AD

919 sampled the material; AR, CR, AV, OG, MA, LM, ML, LB, SGOV performed the molecular

920 work; SGOV, AC, OG, MG, LB, EJ, GD analyzed the data. All co-authors discussed the

921 results. The manuscript was written by SGOV, AC, EJ, OG with critical inputs from other co922 authors.

923

924

925

926

927 


\section{Figures and Tables}

929

a.

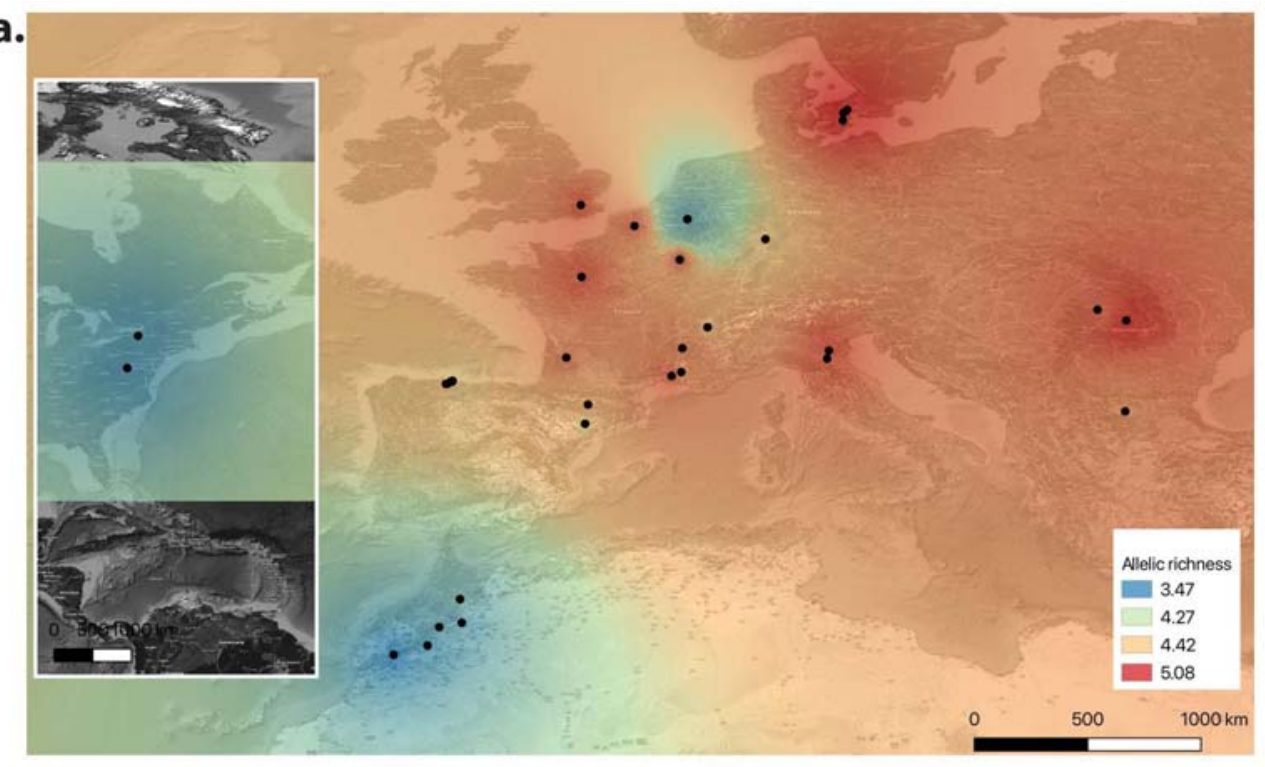

b.

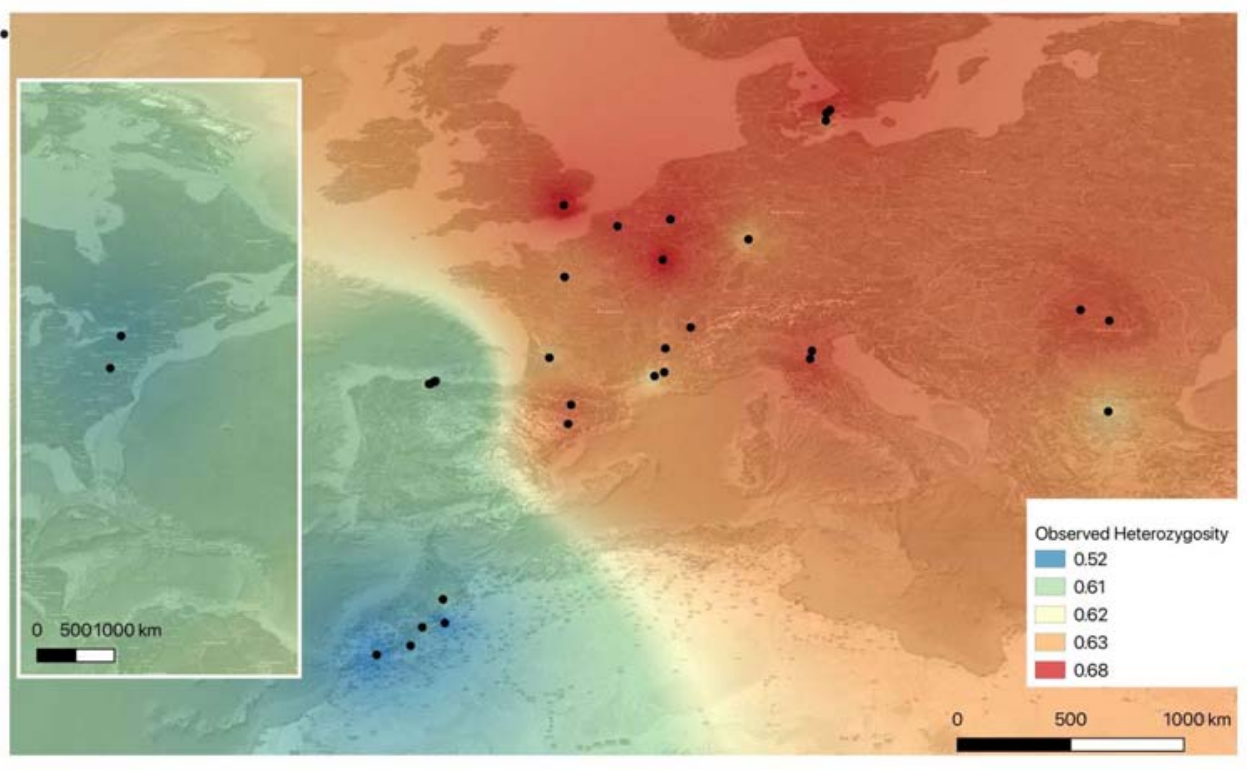

931 Figure 1. Spatial genetic diversity of Dysaphis plantaginea in Europe, Morocco and

932 North America ( $N=$ 582, clones were excluded, 52 sites, 30 SSR markers). a. Map of

933 allelic richness per site. b. Map of observed heterozygosity. Sites with a sample size below

934 five individuals are not represented on this map. Each dot is a site (i.e., orchard). Red means

935 high allelic richness, blue means low. 

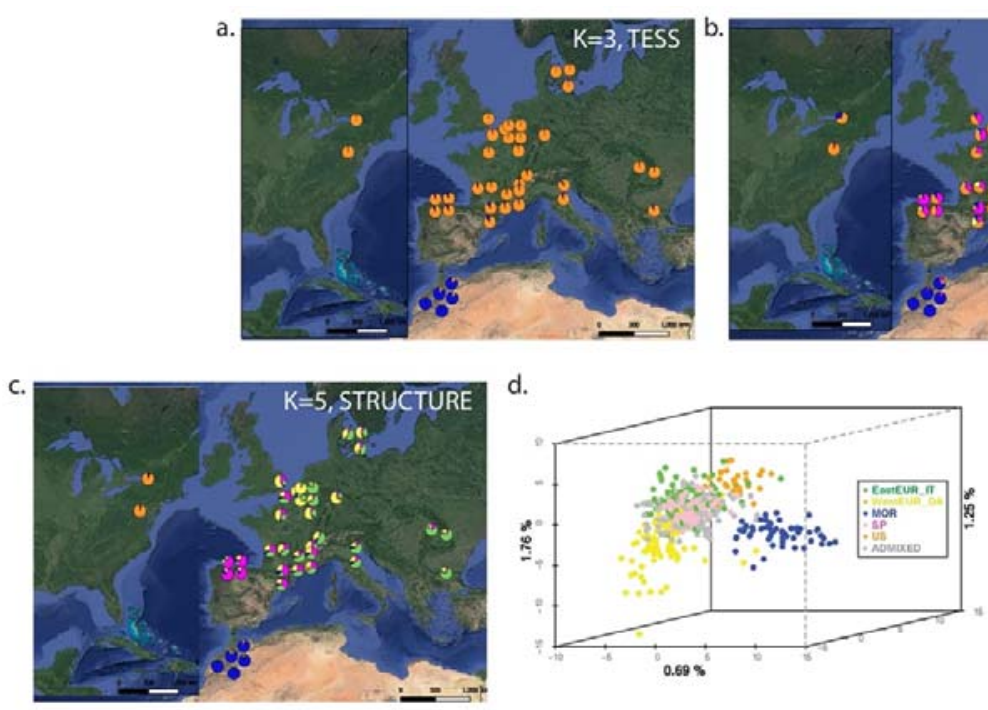

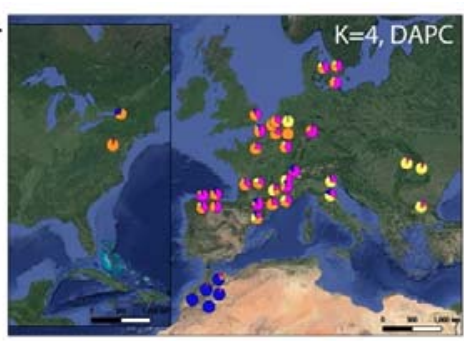

e.

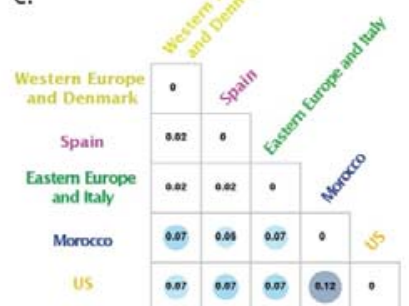

940 Dysaphis plantaginea in Europe, Morocco and North America $(N=582$ individuals, 52

941 sites, 30 SSR markers). Spatial population structure inferred with a. TESS $(K=3)$, b.

942 Discriminant Analysis of Principal Components $(K=4)$, c. with STRUCTURE $(K=5)$. Each

943 figure includes i) a map with each pie chart representing the mean membership coefficients

944 for each site, and, ii) a barplot including each individual represented by a vertical bar

945 partitioned into $K$ segments representing the proportion of ancestry of its genome from those

$946 K$ clusters. d. Principal component analysis including the 582 individuals; each individual is

947 colored according to its membership > 0.625 to one of the five Dysaphis plantaginea

948 populations detected with STRUCTURE (individuals with a membership coefficient $<62.5 \%$

949 to a given cluster is referred as "admixed"). e. Genetic differentiation $\left(F_{S T}\right)$ estimates among

950 the five populations detected with STRUCTURE. US: United States of America; MA:

951 Morocco; BG: Bulgaria; IT: Italy; RO: Romania; SP: Spain; FR: France; DE: Germany; BE:

952 Belgium; UK: United Kingdom; DK: Denmark. 
Table 1. Summary statistics obtained for the five Dysaphis plantaginea populations (i.e., cluster including individuals with a membership coefficient $>\mathbf{6 2 . 5 \%}$ to a given cluster $)$ inferred with STRUCTURE $(\boldsymbol{K}=\mathbf{5})$, based on 30 SSR markers and three concatenated genes $(C O 1$, Cytb and $\operatorname{TrpB}$ ), 67 D. plantaginea individuals), respectively (left and the right sections of the table).

\begin{tabular}{|c|c|c|c|c|c|c|c|c|c|c|c|c|c|c|c|}
\hline Population & $N$ & $\boldsymbol{H}_{O}$ & $\boldsymbol{H}_{E}$ & $F_{I S}$ & $\begin{array}{c}A_{R} \\
(N=28)\end{array}$ & $\begin{array}{c}A_{P} \\
(N=28)\end{array}$ & $S p$ & Nseq & $\mathrm{NH}$ & $H D$ & $S$ & $\pi$ & $\theta$ & $\begin{array}{c}\text { Tajima's } \\
\text { D }\end{array}$ & Fu's Fs \\
\hline Eastern European and Italian & 114 & 0.68 & 0.77 & 0.12 & 7.77 & 1.65 & $0.0006^{\mathrm{n} . \mathrm{s}}$ & 34 & 6 & 0.59 & 6 & 0.0005 & 0.0008 & $-0.960^{\mathrm{n} . \mathrm{s}}$ & $0.550^{\mathrm{n.s}}$ \\
\hline Western European and Danish & 89 & 0.65 & 0.74 & 0.12 & 7.26 & 1.17 & 0.0019 & 10 & 4 & 0.67 & 3 & 0.0006 & 0.0005 & $0.120^{\mathrm{n} . \mathrm{s}}$ & $0.880^{\mathrm{n} . \mathrm{s}}$ \\
\hline Spanish & 113 & 0.61 & 0.71 & 0.14 & 6.80 & 0.92 & 0.0003 & 19 & 5 & 0.71 & 4 & 0.0006 & 0.0006 & $-0.001^{\mathrm{n} . \mathrm{s}}$ & $0.842^{\mathrm{n.s}}$ \\
\hline Moroccan & 63 & 0.53 & 0.61 & 0.13 & 5.42 & 0.60 & -0.0038 & 2 & 2 & 0.67 & 1 & 0.0004 & 0.0003 & $1.630^{\mathrm{n} . \mathrm{s}}$ & $1.280^{\mathrm{n} . \mathrm{s}}$ \\
\hline American & 28 & 0.57 & 0.64 & 0.10 & 4.70 & 0.42 & - & 2 & 2 & 0 & 0 & 0 & 0 & 0 & 0 \\
\hline
\end{tabular}

$N$ : number of individuals, $H o$ and $H e$ : observed and expected heterozygosity, $F_{I S}$ : inbreeding coefficient, $* * * P$-value $<0.0001, A_{R}$ and $A_{P}$ : allelic richness and private allelic richness, respectively, corrected by the rarefaction method, estimated for a sample size of 28 ; $S p=$ spatial parameter; the number of individuals from different geographic locations is too low in the American population to compute the $S p$ parameter. Distribution of haplotypes and molecular diversity based on the sequence markers $C O 1, C y t B$ and $\operatorname{Trp} B$ from 67 individuals from different populations based on the genetic structure inferred with STRUCTURE. Nseq = Number of sequences; $N H$ : number of haplotypes; HD: haplotype diversity; $S=$ number of polymorphic sites; $\pi=$ Nei's nucleotide diversity index; $\theta=$ Watterson's diversity index $\theta$; n.s. $=$ not significant. 


\section{References}

Aketarawong, N., Guglielmino, C. R., Karam, N., Falchetto, M., Manni, M., Scolari, F., ... Malacrida, A. R. (2014). The oriental fruitfly Bactrocera dorsalis ss in East Asia: Disentangling the different forces promoting the invasion and shaping the genetic make-up of populations. Genetica, 142(3), 201-213.

Altschul, S. F., Gish, W., Miller, W., Myers, E. W., \& Lipman, D. J. (1990). Basic local alignment search tool. Journal of Molecular Biology, 215(3), 403-410.

Angert, A. L., Bontrager, M. G., \& Ågren, J. (2020). What Do We Really Know About Adaptation at Range Edges? Annual Review of Ecology, Evolution, and Systematics, 51(1), 341-361. doi: 10.1146/annurev-ecolsys-012120-091002

Aslan, B., \& Karaca, İ. (2005). Fruit tree Aphids and their natural enemies in Isparta region, Turkey. Journal of Pest Science, 78(4), 227-229. doi: 10.1007/s10340-005$0097-2$

Austerlitz, F., Jung-Muller, B., Godelle, B., \& Gouyon, P.-H. (1997). Evolution of coalescence times, genetic diversity and structure during colonization. Theoretical Population Biology, 51(2), 148-164.

Barbagallo, S., Cocuzza, G., Cravedi, P., \& Komazaki, S. (2007). 29 IPM Case Studies: Deciduous Fruit Trees. Aphids as Crop Pests, 651.

Bašilova, J., \& Rakauskas, R. (2012). Phylogenetic relationships of Dysaphis pyri (BOYER DE FONSCOLOMBE) and Dysaphis reaumuri (MORDVILKO)(Hemiptera, Sternorrhyncha: Aphididae): COI and EF-1 $\alpha$ evidence. Organisms Diversity \& Evolution, 12(2), 197-204.

Bertorelle, G., Benazzo, A., \& Mona, S. (2010). ABC as a flexible framework to estimate demography over space and time: Some cons, many pros. Molecular Ecology, 19(13), 2609-2625. 
Blackman, R. L., \& Eastop, V. F. (2000). Aphids on the world's crops: An identification and information guide. John Wiley \& Sons Ltd.

Blakeslee, A. M. H., Haram, L. E., Altman, I., Kennedy, K., Ruiz, G. M., \& Miller, A. W. (2019). Founder effects and species introductions: A host versus parasite perspective. Evolutionary Applications, 13(3), 559-574. PubMed (32431736). doi:

\subsection{1/eva.12868}

Blommers, L. H. M., Helsen, H. H. M., \& Vaal, F. W. N. M. (2004). Life history data of the rosy apple aphid Dysaphis plantaginea (Pass.) (Homopt., Aphididae) on plantain and as migrant to apple. Journal of Pest Science, 77(3), 155-163. doi: 10.1007/s10340004-0046-5

Bloomquist, E. W., Lemey, P., \& Suchard, M. A. (2010). Three roads diverged? Routes to phylogeographic inference. Trends in Ecology \& Evolution, 25(11), 626-632. doi: https://doi.org/10.1016/j.tree.2010.08.010

Bonnemaison, L. (1959). Le puceron cendré du pommier (Dysaphis plantaginea Pass.). Morphologie et biologie. Méthodes de lutte. Annales Des Épiphyties, (3), 257-320.

Brady, C. M., Asplen, M. K., Desneux, N., Heimpel, G. E., Hopper, K. R., Linnen, C. R., ... White, J. A. (2014). Worldwide populations of the aphid Aphis craccivora are infected with diverse facultative bacterial symbionts. Microbial Ecology, 67(1), 195204.

Breiman, L. (2001). Random Forests. Machine Learning, 45(1), 5-32. doi: 10.1023/A:1010933404324

Buchner, P. (1965). Endosymbiosis of Animals with Plant Microorganisms. In H. Malke (Ed.), Zeitschrift für allgemeine Mikrobiologie (Vol. 7, pp. 168-168). ohn Wiley \& Sons, Inc.: Interscience Publ. Retrieved from https://onlinelibrary.wiley.com/doi/abs/10.1002/jobm.19670070219 
CAB International. (2020). Dysaphis plantaginea. [Distribution map]. Nosworthy Way, Wallingford, Oxfordshire, OX10 8DE, UK.: CAB International Wallingford UK. Retrieved from https://www.cabi.org/isc/abstract/20056600429

Celton, J. M., Chagne, D., Tustin, S. D., Terakami, S., Nishitani, C., Yamamoto, T., \& Gardiner, S. E. (2009). Update on comparative genome mapping between Malus and Pyrus. BMC Res Notes, 2. doi: 10.1186/1756-0500-2-182

Chapuis, M.-P., Raynal, L., Plantamp, C., Meynard, C. N., Blondin, L., Marin, J.-M., \& Estoup, A. (2020). A young age of subspecific divergence in the desert locust inferred by ABC random forest. Molecular Ecology, 1-17. doi: 10.1111/mec.15663

Chen, C., Durand, E., Forbes, F., \& François, O. (2007). Bayesian clustering algorithms ascertaining spatial population structure: A new computer program and a comparison study. Molecular Ecology Notes, 7(5), 747-756.

Choi, H., Shin, S., Jung, S., Clarke, D. J., \& Lee, S. (2018). Molecular phylogeny of Macrosiphini (Hemiptera: Aphididae): An evolutionary hypothesis for the Pterocomma-group habitat adaptation. Molecular Phylogenetics and Evolution, 121, 12-22. doi: 10.1016/j.ympev.2017.12.021

Coeur d'acier, A., Cruaud, A., Artige, E., Genson, G., Clamens, A.-L., Pierre, E., ... Rasplus, J.-Y. (2014). DNA Barcoding and the Associated PhylAphidB@se Website for the Identification of European Aphids (Insecta: Hemiptera: Aphididae). PLOS ONE, 9(6), 1-16. doi: 10.1371/journal.pone.0097620

Cornille, A., Antolín, F., Garcia, E., Vernesi, C., Fietta, A., Brinkkemper, O., ... RoldánRuiz, I. (2019). A Multifaceted Overview of Apple Tree Domestication. Trends in Plant Science, 24(8), 770-782. doi: https://doi.org/10.1016/j.tplants.2019.05.007

Cornille, A., Feurtey, A., Gélin, U., Ropars, J., Misvanderbrugge, K., Gladieux, P., \& Giraud, T. (2015). Anthropogenic and natural drivers of gene flow in a temperate wild fruit 
tree: A basis for conservation and breeding programs in apples. Evolutionary Applications, n/a-n/a. doi: 10.1111/eva.12250

Cornille, A., Giraud, T., Smulders, M. J. M., Roldán-Ruiz, I., \& Gladieux, P. (2014). The domestication and evolutionary ecology of apples. Trends in Genetics, 30(2), 57-65. doi: 10.1016/j.tig.2013.10.002

Cornuet, J. M., \& Luikart, G. (1996). Description and power analysis of two tests for detecting recent population bottlenecks from allele frequency data. Genetics, 144(4), 2001-2014.

Csillery, K., Blum, M., \& Francois, O. (2012). Tools for Approximate Bayesian Computation (ABC) http://cran.r-project.org/web/packages/abc/index.html.

Csilléry, K., Blum, M. G. B., Gaggiotti, O. E., \& François, O. (2010). Approximate Bayesian computation (ABC) in practice. Trends in Ecology \& Evolution, 25(7), 410-418.

Currat, M., \& Excoffier, L. (2005). The effect of the Neolithic expansion on European molecular diversity. Proceedings of the Royal Society B: Biological Sciences, 272(1564), 679-688. doi: 10.1098/rspb.2004.2999

Dray, S., \& Dufour, A.-B. (2007). The ade4 Package: Implementing the Duality Diagram for Ecologists. Journal of Statistical Software; Vol 1, Issue 4 (2007). doi: 10.18637/jss.v022.i04

Durand, E., Chen, C., \& François, O. (2009). Tess version 2.3-Reference Manual August 2009. 30.

Egea, R., Casillas, S., \& Barbadilla, A. (2008). Standard and generalized McDonaldKreitman test: A website to detect selection by comparing different classes of DNA sites. Nucleic Acids Research, 36(Web Server), W157-W162. doi: 10.1093/nar/gkn337 
Escudié, F., Auer, L., Bernard, M., Mariadassou, M., Cauquil, L., Vidal, K., ... Pascal, G. (2018). FROGS: Find, Rapidly, OTUs with Galaxy Solution. Bioinformatics, 34(8), 1287-1294. doi: 10.1093/bioinformatics/btx791

Estoup, A. A., Raynal, L., Verdu, P., \& Marin, J.-M. (2018). Model choice using Approximate Bayesian Computation and Random Forests: Analyses based on model grouping to make inferences about the genetic history of Pygmy human populations. Journal de La Societe Française de Statistique, 159(3), 167-190.

Estoup, A., \& Guillemaud, T. (2010). Reconstructing routes of invasion using genetic data: Why, how and so what? Molecular Ecology, 19(19), 4113-4130. doi: 10.1111/j.1365294X.2010.04773.x

Evanno, G., Regnaut, S., \& Goudet, J. (2005). Detecting the number of clusters of individuals using the software STRUCTURE: a simulation study. Molecular Ecology, 14(8), 2611-2620.

Excoffier, L., \& Foll, M. (2011). fastsimcoal: A continuous-time coalescent simulator of genomic diversity under arbitrarily complex evolutionary scenarios. Bioinformatics, 27(9), 1332-1334. doi: 10.1093/bioinformatics/btr124

Excoffier, L., Foll, M., \& Petit, R. J. (2009). Genetic consequences of range expansions. Annual Review of Ecology, Evolution, and Systematics, 40(1), 481-501. doi: 10.1146/annurev.ecolsys.39.110707.173414

Excoffier, L., \& Lischer, H. E. L. (2010). Arlequin suite ver 3.5: A new series of programs to perform population genetics analyses under Linux and Windows. Molecular Ecology Resources, 10(3), 564-567. doi: 10.1111/j.1755-0998.2010.02847.x

Fang, F., Chen, J., Jiang, L., Qu, Y., \& Qiao, G. (2018). Genetic origin and dispersal of the invasive soybean aphid inferred from population genetic analysis and approximate 
Bayesian computation. Integrative Zoology, 13(5), 536-552. doi: 10.1111/17494877.12307

Fontaine, M., Labbé, F., Dussert, Y., Delière, L., Richart-Cervera, S., Giraud, T. E., \& Delmotte, F. (2020). Europe as a bridgehead in the worldwide invasion history of grapevine downy mildew, Plasmopara viticola. doi: 10.1101/2020.09.22.307678

Foottit, R. G., Halbert, S. E., Miller, G. L., Maw, E., \& Russell, L. M. (2006). Adventive aphids (Hemiptera: Aphididae) of America north of Mexico. Retrieved from https://pubag.nal.usda.gov/catalog/8716

Frago, E., Mala, M., Weldegergis, B. T., Yang, C., McLean, A., Godfray, H. C. J., ... Dicke, M. (2017). Symbionts protect aphids from parasitic wasps by attenuating herbivoreinduced plant volatiles. Nature Communications, 8(1), 1860. doi: 10.1038/s41467017-01935-0

Frago, E., Zytynska, S. E., \& Fatouros, N. E. (2020). Microbial symbionts of herbivorous species across the insect tree. Mechanisms Underlying Microbial Symbiosis, 111-159. doi: 10.1016/bs.aiip.2020.04.002

Fraimout, A., Debat, V., Fellous, S., Hufbauer, R. A., Foucaud, J., Pudlo, P., ... Estoup, A. (2017). Deciphering the Routes of invasion of Drosophila suzukii by Means of ABC Random Forest. Molecular Biology and Evolution, 34(4), 980-996. PMC (PMC5400373). doi: 10.1093/molbev/msx050

Francis, R. (2016). POPHELPER: An R package and web app to analyse and visualise population structure. Molecular Ecology Resources, 17, n/a-n/a. doi: 10.1111/17550998.12509

François, O., Blum, M. G. B., Jakobsson, M., \& Rosenberg, N. A. (2008). Demographic History of European Populations of Arabidopsis thaliana. PLOS Genetics, 4(5), e1000075. doi: 10.1371/journal.pgen.1000075 
Fu, Y.-X. (1997). Statistical Tests of Neutrality of Mutations Against Population Growth, Hitchhiking and Background Selection. Genetics, 147(2), 915.

Garnas, J., R., Auger-Rozenberg, M.-A., Roques, A., Bertelsmeier, C., Wingfield, M. J., Saccaggi, D. L., ... Slippers, B. (2016). Complex patterns of global spread in invasive insects: Eco-evolutionary and management consequences. Biological Invasions, 18(4), 935-952. doi: 10.1007/s10530-016-1082-9

Giordano, R., Donthu, R. K., Zimin, A. V., Julca Chavez, I. C., Gabaldon, T., van Munster, M., ... Zhan, S. (2020). Soybean aphid biotype 1 genome: Insights into the invasive biology and adaptive evolution of a major agricultural pest. Insect Biochemistry and Molecular Biology, 120, 103334. doi: 10.1016/j.ibmb.2020.103334

Gladieux, P., Feurtey, A., Hood, M. E., Snirc, A., Clavel, J., Dutech, C., ... Giraud, T. (2015). The population biology of fungal invasions. Molecular Ecology, 24(9), 19691986. doi: $10.1111 / \mathrm{mec} .13028$

Gladieux, Pierre, Ropars, J., Badouin, H., Branca, A., Aguileta, G., de Vienne, D. M., ... Giraud, T. (2014). Fungal evolutionary genomics provides insight into the mechanisms of adaptive divergence in eukaryotes. Molecular Ecology, 23(4), 753773. doi: $10.1111 / \mathrm{mec} .12631$

Guillemaud, T., Blin, A., Simon, S., Morel, K., \& Franck, P. (2011). Weak Spatial and Temporal Population Genetic Structure in the Rosy Apple Aphid, Dysaphis plantaginea, in French Apple Orchards. PLoS ONE, 6(6), e21263. doi:

10.1371/journal.pone.0021263

Hardy, O. J., \& Vekemans, X. (2002). SPAGeDI: a versatile computer program to analyse spatial genetic structure at the individual or population levels. Molecular Ecology Notes, 2(4), 618-620. 
Harris, S. A., Robinson, J. P., \& Juniper, B. E. (2002). Genetic clues to the origin of the apple. Trends Genet, 18(8), 426-430.

Haynes, S., Darby, A. C., Daniell, T. J., Webster, G., van Veen, F. J. F., Godfray, H. C. J., ... Douglas, A. E. (2003). Diversity of Bacteria Associated with Natural AphidPopulations. Applied and Environmental Microbiology, 69(12), 7216-7223. doi: 10.1128/AEM.69.12.7216-7223.2003

Henry, L. M., Maiden, M. C. J., Ferrari, J., \& Godfray, H. C. J. (2015). Insect life history and the evolution of bacterial mutualism. Ecology Letters, 18(6), 516-525. doi: 10.1111/ele. 12425

Hickerson, M. J., Carstens, B. C., Cavender-Bares, J., Crandall, K. A., Graham, C. H., Johnson, J. B., ... Yoder, A. D. (2010). Phylogeography's past, present, and future: 10 years after. Molecular Phylogenetics and Evolution, 54(1), 291-301. doi: 10.1016/j.ympev.2009.09.016

Hoffmann, B. D., \& Courchamp, F. (2016). Biological invasions and natural colonisations: Are they that different? NeoBiota, 29, 1-14. doi: 10.3897/neobiota.29.6959

Holman, J. (2009). Host Plant Catalog of Aphids: Palaearctic Region (Springer Nature eReference).

Huelsenbeck, J. P., \& Ronquist, F. (2001). MRBAYES: Bayesian inference of phylogenetic trees. Bioinformatics, 17(8), 754-755. doi: 10.1093/bioinformatics/17.8.754

Jakobsson, M., \& Rosenberg, N. A. (2007). CLUMPP: a cluster matching and permutation program for dealing with label switching and multimodality in analysis of population structure. Bioinformatics, 23(14), 1801-1806. doi: 10.1093/bioinformatics/btm233

Jombart, T., \& Collins, C. (2015). A tutorial for Discriminant Analysis of Principal Components (DAPC) using adegenet 2.0.0. 43. 
Jombart, T., Devillard, S., \& Balloux, F. (2010). Discriminant analysis of principal components: A new method for the analysis of genetically structured populations. BMC Genetics, 11(1), 94. doi: 10.1186/1471-2156-11-94

Jousselin, E., Clamens, A.-L., Galan, M., Bernard, M., Maman, S., Gschloessl, B., ... Coeur d'acier, A. (2016). Assessment of a 16S rRNA amplicon Illumina sequencing procedure for studying the microbiome of a symbiont-rich aphid genus. Molecular Ecology Resources, 16(3), 628-640. doi: 10.1111/1755-0998.12478

Jousselin, Emmanuelle, Desdevises, Y., \& Coeur d'acier, A. (2009). Fine-scale cospeciation between Brachycaudus and Buchnera aphidicola: Bacterial genome helps define species and evolutionary relationships in aphids. Proceedings of the Royal Society B: Biological Sciences, 276(1654), 187-196. doi: 10.1098/rspb.2008.0679

Kadyrbekov, Rk. (2002). About the aphid fauna (Homoptera Aphididae) of West Tien-Shan (Kazakhstan part). Tethys Entomological Research, (4), 65-76.

Kalinowski, S. T. (2011). The computer program STRUCTURE does not reliably identify the main genetic clusters within species: Simulations and implications for human population structure. Heredity, 106(4), 625-632.

Kim, H., Hoelmer, K., \& Lee, S. (2016). Population genetics of the soybean aphid in North America and East Asia: Test for introduction between native and introduced populations. Biological Invasions, 19. doi: 10.1007/s10530-016-1299-7

Kirk, H., Dorn, S., \& Mazzi, D. (2013). Molecular genetics and genomics generate new insights into invertebrate pest invasions. Evolutionary Applications, 6(5), 842-856. doi: 10.1111/eva.12071

Kozich, J. J., Westcott, S. L., Baxter, N. T., Highlander, S. K., \& Schloss, P. D. (2013). Development of a Dual-Index Sequencing Strategy and Curation Pipeline for Analyzing Amplicon Sequence Data on the MiSeq Illumina Sequencing Platform. 
Applied and Environmental Microbiology, 79(17), 5112-5120. doi:

10.1128/AEM.01043-13

Kumar, S., Stecher, G., \& Tamura, K. (2016). MEGA7: Molecular Evolutionary Genetics Analysis Version 7.0 for Bigger Datasets. Molecular Biology and Evolution, 33(7), 1870-1874. doi: 10.1093/molbev/msw054

Lawson Handley, L.-J., Estoup, A., Evans, D. M., Thomas, C. E., Lombaert, E., Facon, B., ... Roy, H. E. (2011). Ecological genetics of invasive alien species. BioControl, 56(4), 409-428. doi: 10.1007/s10526-011-9386-2

Leclair, M., Pons, I., Mahéo, F., Morlière, S., Simon, J.-C., \& Outreman, Y. (2016). Diversity in symbiont consortia in the pea aphid complex is associated with large phenotypic variation in the insect host. Evolutionary Ecology, 30(5), 925-941. doi: $10.1007 / \mathrm{s} 10682-016-9856-1$

Lenhart, P. A., \& White, J. A. (2020). Endosymbionts facilitate rapid evolution in a polyphagous herbivore. Journal of Evolutionary Biology, 33(10), 1507-1511. doi: 10.1111/jeb.13697

Loiselle, B. A., Sork, V. L., Nason, J., \& Graham, C. (1995). Spatial genetic structure of a tropical understory shrub, Psychotria officinalis (Rubiaceae). American Journal of Botany, 82(11), 1420-1425.

Loxdale, H. D., Hardie, J., Halbert, S., Foottit, R., Kidd, N. A. C., \& Carter, C. I. (1993). The relative importance of short- and long-range movement of flying aphids. Biological Reviews, 68(2), 291-311. doi: 10.1111/j.1469-185X.1993.tb00998.x

Magoč, T., \& Salzberg, S. L. (2011). FLASH: Fast length adjustment of short reads to improve genome assemblies. Bioinformatics, 27(21), 2957-2963. doi: 10.1093/bioinformatics/btr507 
Mahé, F., Rognes, T., Quince, C., Vargas, C. de, \& Dunthorn, M. (2014). Swarm: Robust and fast clustering method for amplicon-based studies. PeerJ, 2, e593. doi: 10.7717/peerj.593

Martin, M. (2011). Cutadapt removes adapter sequences from high-throughput sequencing reads. EMBnet.Journal, 17(1), 10-12. doi: 10.14806/ej.17.1.200

McDonald, J. H., \& Kreitman, M. (1991). Adaptive protein evolution at the Adh locus in Drosophila. Nature, 351(6328), 652-654. doi: 10.1038/351652a0

Meirmans, P. G., \& Van Tienderen, P. H. (2004). Genotype and genodive: Two programs for the analysis of genetic diversity of asexual organisms. Mol Ecol Notes, 4(4), 792-794.

Menozzi, P., Piazza, A., \& Cavalli-Sforza, L. (1978). Synthetic maps of human gene frequencies in Europeans. Science, 201(4358), 786-792. doi: 10.1126/science.356262

Mizrahi-Man, O., Davenport, E. R., \& Gilad, Y. (2013). Taxonomic Classification of Bacterial 16S rRNA Genes Using Short Sequencing Reads: Evaluation of Effective Study Designs. PLOS ONE, 8(1), e53608. doi: 10.1371/journal.pone.0053608

Morales $\square$ Hojas, R., Sun, J., Iraizoz, F. A., Tan, X., \& Chen, J. (2020). Contrasting population structure and demographic history of cereal aphids in different environmental and agricultural landscapes. Ecology and Evolution, 10(18), 96479662. doi: 10.1002/ece3.6565

Nei, M. (1987). Molecular Evolutionary Genetics. Columbia University Press. Retrieved from https://books.google.es/books?id=UhRSsLkjxDgC

Oliver, K. M., Degnan, P. H., Burke, G. R., \& Moran, N. A. (2010). Facultative symbionts in aphids and the horizontal transfer of ecologically important traits. Annu Rev Entomol, 55. doi: 10.1146/annurev-ento-112408-085305

Peccoud, J., Figueroa, C. C., Silva, A. X., Ramirez, C. C., Mieuzet, L., Bonhomme, J., ... Simon, J.-C. (2008). Host range expansion of an introduced insect pest through 
multiple colonizations of specialized clones. Molecular Ecology, 17(21), 4608-4618. doi: 10.1111/j.1365-294X.2008.03949.x

Piffaretti, J., Clamens, A.-L., Vanlerberghe $\square$ masutti, F., Gupta, R. K., Call, E., Halbert, S., \& Jousselin, E. (2013). Regular or covert sex defines two lineages and worldwide superclones within the leaf-curl plum aphid (Brachycaudus helichrysi, Kaltenbach). Molecular Ecology, 22(15), 3916-3932. doi: 10.1111/mec.12371

Piry, S., Luikart, G., \& Cornuet, J. M. (1999). Computer note. BOTTLENECK: a computer program for detecting recent reductions in the effective size using allele frequency data. Journal of Heredity, 90(4), 502-503. doi: 10.1093/jhered/90.4.502

Popkin, M., Piffaretti, J., Clamens, A.-L., Qiao, G.-X., Chen, J., Vitalis, R., ... Jousselin, E. (2017). Large-scale phylogeographic study of the cosmopolitan aphid pest Brachycaudus helichrysi reveals host plant associated lineages that evolved in allopatry. Biological Journal of the Linnean Society, 120(1), 102-114. doi: 10.1111/bij. 12869

Posada, D., \& Crandall, K. A. (2001). Intraspecific gene genealogies: Trees grafting into networks. Trends in Ecology \& Evolution, 16(1), 37-45. doi: 10.1016/S01695347(00)02026-7

Pritchard, J. K., Stephens, M., \& Donnelly, P. (2000). Inference of population structure using multilocus genotype data. Genetics, 155(2), 945-959.

Prugnolle, F., Manica, A., \& Balloux, F. (2005). Geography predicts neutral genetic diversity of human populations. Current Biology, 15(5), R159-R160. doi:

10.1016/j.cub.2005.02.038

Pudlo, P., Marin, J.-M., Estoup, A., Cornuet, J.-M., Gautier, M., \& Robert, C. P. (2016). Reliable ABC model choice via random forests. Bioinformatics, 32(6), 859-866. doi: 10.1093/bioinformatics/btv684 
Puechmaille, S. J. (2016). The program structure does not reliably recover the correct population structure when sampling is uneven: Subsampling and new estimators alleviate the problem. Molecular Ecology Resources, 16(3), 608-627. doi: 10.1111/1755-0998.12512

Raynal, L., Marin, J.-M., Pudlo, P., Ribatet, M., Robert, C. P., \& Estoup, A. (2019). ABC random forests for Bayesian parameter inference. Bioinformatics, 35(10), 1720-1728. doi: 10.1093/bioinformatics/bty867

Rebijith, K. B., Hande, R., Joshi, S., Surveswaran, S., Ramamurthy, V., \& Kumar, N. (2017). Reconstructing the macroevolutionary patterns of aphids (Hemiptera: Aphididae) using nuclear and mitochondrial DNA sequences. Biological Journal of the Linnean Society. doi: 10.1093/biolinnean/blx020

Ripley, B. D., \& Ripley, B. D. (2001). The R project in statistical computing. MSOR Connections.

Rispe, C., Legeai, F., Nabity, P. D., Fernández, R., Arora, A. K., Baa-Puyoulet, P., ... Tagu, D. (2020). The genome sequence of the grape phylloxera provides insights into the evolution, adaptation, and invasion routes of an iconic pest. BMC Biology, 18(1), 90. doi: 10.1186/s12915-020-00820-5

Rius, M., \& Darling, J. (2014). How important is intraspecific genetic admixture to the success of colonising populations? Trends in Ecology \& Evolution, 29. doi: 10.1016/j.tree.2014.02.003

Rognes, T., Flouri, T., Nichols, B., Quince, C., \& Mahé, F. (2016). VSEARCH: A versatile open source tool for metagenomics. PeerJ, 4, e2584. doi: 10.7717/peerj.2584

Rousset, F. (2008). Genepop'007: A complete re-implementation of the genepop software for Windows and Linux. Molecular Ecology Resources, 8(1), 103-106. 
Roux, C., \& Pannell, J. R. (2015). Inferring the mode of origin of polyploid species from next-generation sequence data. Molecular Ecology, (24), 1047-1059. doi:

$10.1111 /$ mec.13078

Rozas, J., Sànchez-DelBarrio, J. C., Messeguer, X., \& Rozas, R. (2003). DnaSP, DNA polymorphism analyses by the coalescent and other methods. Bioinformatics, 19(18), 2496-2497. doi: 10.1093/bioinformatics/btg359

Russell, J. A., Weldon, S., Smith, A. H., Kim, K. L., Hu, Y., Łukasik, P., ... Oliver, K. M. (2013). Uncovering symbiont-driven genetic diversity across North American pea aphids. Molecular Ecology, 22(7), 2045-2059. doi: 10.1111/mec.12211

Simon, J.-C., Rispe, C., \& Sunnucks, P. (2002). Ecology and evolution of sex in aphids. Trends in Ecology \& Evolution, 17(1), 34-39. doi: 10.1016/S0169-5347(01)02331-X

Simon, J.-C., Stoeckel, S., \& Tagu, D. (2010). Evolutionary and functional insights into reproductive strategies of aphids. Comptes Rendus Biologies, 333(6), 488-496. doi: 10.1016/j.crvi.2010.03.003

Sow, A., Brévault, T., Benoit, L., Chapuis, M.-P., Galan, M., Coeur D’acier, A., ... Haran, J. (2019). Deciphering host-parasitoid interactions and parasitism rates of crop pests using DNA metabarcoding. Scientific Reports, 9(1), 3646. doi: 10.1038/s41598-01940243-z

Spengler, R. N. (2019). Origins of the Apple: The Role of Megafaunal Mutualism in the Domestication of Malus and Rosaceous Trees. Frontiers in Plant Science, 10. doi: 10.3389/fpls.2019.00617

Stekolshchikov, A. V. (2006). Aphids of the genus Dysaphis Börner (Homoptera, Aphididae) living on plants of the family polygonaceae. Entomological Review, 86(7), 787-805. doi: $10.1134 / \mathrm{S} 0013873806070049$ 
Stukenbrock, E. H. (2016). The Role of Hybridization in the Evolution and Emergence of New Fungal Plant Pathogens. Phytopathology, 106(2), 104-112. doi:

\subsection{4/PHYTO-08-15-0184-RVW}

Stukenbrock, E. H., \& McDonald, B. A. (2008). The Origins of Plant Pathogens in AgroEcosystems. Annual Review of Phytopathology, 46(1), 75-100. doi:

10.1146/annurev.phyto.010708.154114

Szpiech, Z. A., Jakobsson, M., \& Rosenberg, N. A. (2008). ADZE: a rarefaction approach for counting alleles private to combinations of populations. Bioinformatics, 24(21), 24982504. doi: 10.1093/bioinformatics/btn478

Tajima, F. (1989). Statistical method for testing the neutral mutation hypothesis by DNA polymorphism. Genetics, 123(3), 585-595.

Tardío, J., Arnal, A., \& Lázaro, A. (2020). Ethnobotany of the crab apple tree (Malus sylvestris (L.) Mill., Rosaceae) in Spain. Genetic Resources and Crop Evolution. doi: 10.1007/s10722-020-01026-y

Tsuchida, T., Koga, R., Shibao, H., Matsumoto, T., \& Fukatsu, T. (2002). Diversity and geographic distribution of secondary endosymbiotic bacteria in natural populations of the pea aphid, Acyrthosiphon pisum. Molecular Ecology, 11(10), 2123-2135. doi: 10.1046/j.1365-294X.2002.01606.X

Turcotte, M. M., Araki, H., Karp, D. S., Poveda, K., \& Whitehead, S. R. (2017). The ecoevolutionary impacts of domestication and agricultural practices on wild species. Philosophical Transactions of the Royal Society of London B: Biological Sciences, 372(1712). doi: 10.1098/rstb.2016.0033

Vekemans, X., \& Hardy, O. J. (2004). New insights from fine-scale spatial genetic structure analyses in plant populations. Molecular Ecology, 13(4), 921-935. 
Vorburger, C., Lancaster, M., \& Sunnucks, P. (2003). Environmentally related patterns of reproductive modes in the aphid Myzus persicae and the predominance of two ‘superclones’ in Victoria, Australia. Molecular Ecology, 12(12), 3493-3504. doi: 10.1046/j.1365-294X.2003.01998.x

Wang, Y., Hereward, J. P., \& Zhang, G. (2016). High Spatial Genetic Structure and Genetic Diversity in Chinese Populations of Sitobion miscanthi (Hemiptera: Aphididae). Journal of Economic Entomology, 109(1), 375-384. doi: 10.1093/jee/tov294

Warneys, R., Gaucher, M., Robert, P., Aligon, S., Anton, S., Aubourg, S., ... Degrave, A. (2018). Acibenzolar-S-Methyl Reprograms Apple Transcriptome Toward Resistance to Rosy Apple Aphid. Frontiers in Plant Science, 9, 1795. doi: 10.3389/fpls.2018.01795

Watterson, G. A. (1975). On the number of segregating sites in genetical models without recombination. Theoretical Population Biology, 7(2), 256-276.

Watterson, G. A. (1978). The homozygosity test of neutrality. Genetics, 88(2), 405.

Wegmann, D., Leuenberger, C., Neuenschwander, S., \& Excoffier, L. (2010). ABCtoolbox: A versatile toolkit for approximate Bayesian computations. BMC Bioinformatics, 11(1), 116. doi: 10.1186/1471-2105-11-116

Wei, G., Zuorui, S., Zhihong, L., \& Lingwang, G. (2005). Migration and population genetics of the grain aphid Macrosiphum miscanti (Takahashi) in relation to the geographic distance and gene flow. Progress in Natural Science, 15(11), 1000-1004. doi: $10.1080 / 10020070512331343176$

Wilkaniec, B. (1993). The influence of feeding of the rosy apple aphid, Dysaphis plantaginea (Pass.) (Homoptera: Aphididae) on the growth of apple fruits. Roczniki Nauk Rolniczych. Seria E, Ochrona Roślin, 23(1/2), 75-78. 
Xiang, Y., Huang, C.-H., Hu, Y., Wen, J., Li, S., Yi, T., ... Ma, H. (2017). Evolution of Rosaceae Fruit Types Based on Nuclear Phylogeny in the Context of Geological Times and Genome Duplication. Molecular Biology and Evolution, 34(2), 262-281. doi: $10.1093 / \mathrm{molbev} / \mathrm{msw} 242$

Zepeda $\square$ Paulo, F. A., Simon, J. $\square$ C., Ramírez, C. C., Fuentes $\square$ Contreras, E., Margaritopoulos, J. T., Wilson, A. C. C., ... Figueroa, C. C. (2010). The invasion route for an insect pest species: The tobacco aphid in the New World. Molecular Ecology, 19(21), 4738-4752. doi: 10.1111/j.1365-294X.2010.04857.x

Zepeda-Paulo, F., Ortiz-Martínez, S., Silva, A. X., \& Lavandero, B. (2018). Low bacterial community diversity in two introduced aphid pests revealed with $16 \mathrm{~S}$ rRNA amplicon sequencing. PeerJ, 6, e4725. doi: 10.7717/peerj.4725

Zhang, B., Edwards, O., Kang, L., \& Fuller, S. (2014). A multi-genome analysis approach enables tracking of the invasion of a single Russian wheat aphid (Diuraphis noxia) clone throughout the New World. Mol Ecol, 23. doi: 10.1111/mec.12714

Zhou, H.-X., Zhang, R.-M., Tan, X.-M., Tao, Y.-L., Wan, F., Wu, Q., \& Chu, D. (2015). Invasion Genetics of Woolly Apple Aphid (Hemiptera: Aphididae) in China. Journal of Economic Entomology, 108. doi: 10.1093/jee/tov074

Zytynska, S. E., \& Weisser, W. W. (2016). The natural occurrence of secondary bacterial symbionts in aphids. Ecological Entomology, 41(1), 13-26. doi: 10.1111/een.12281 


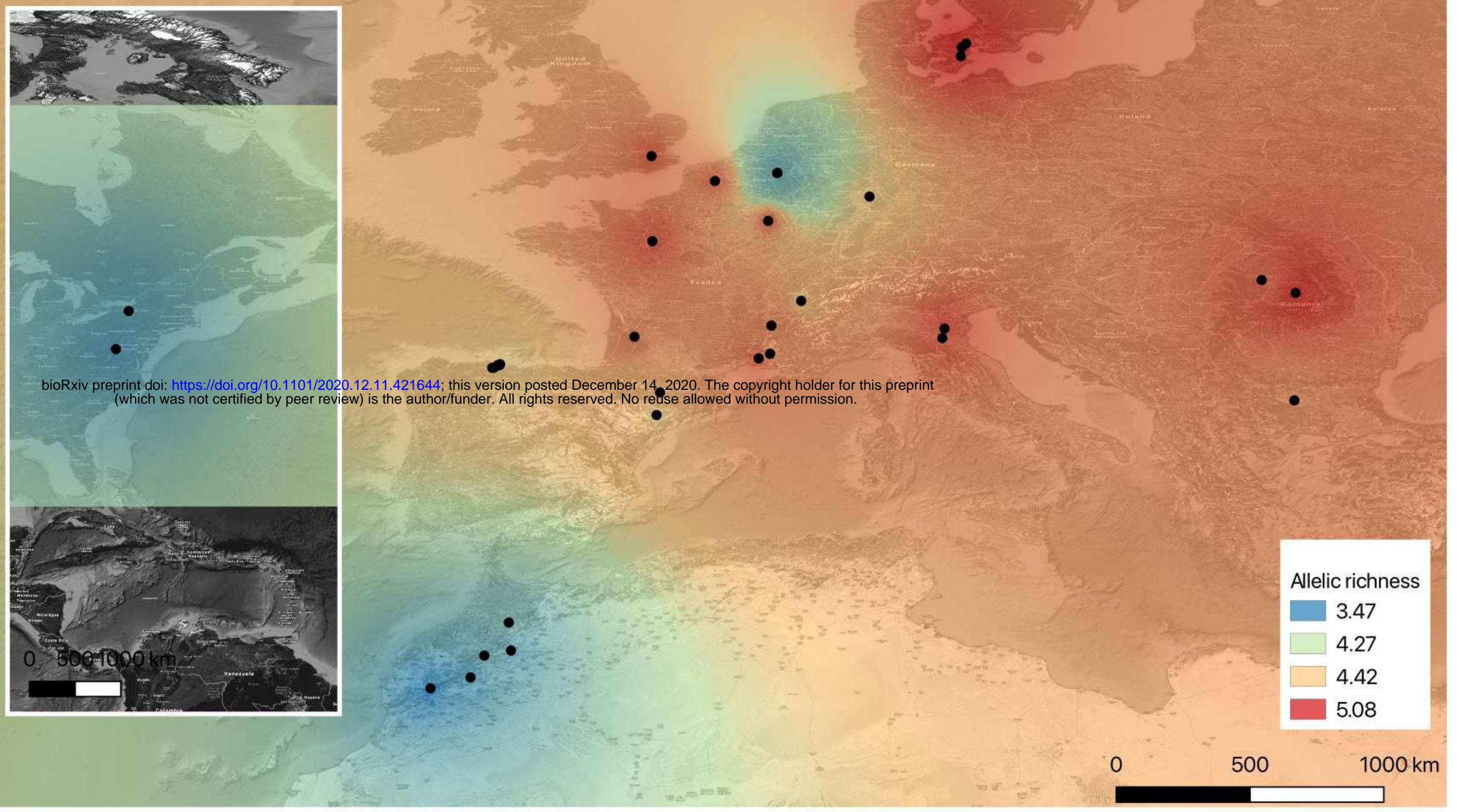

b.
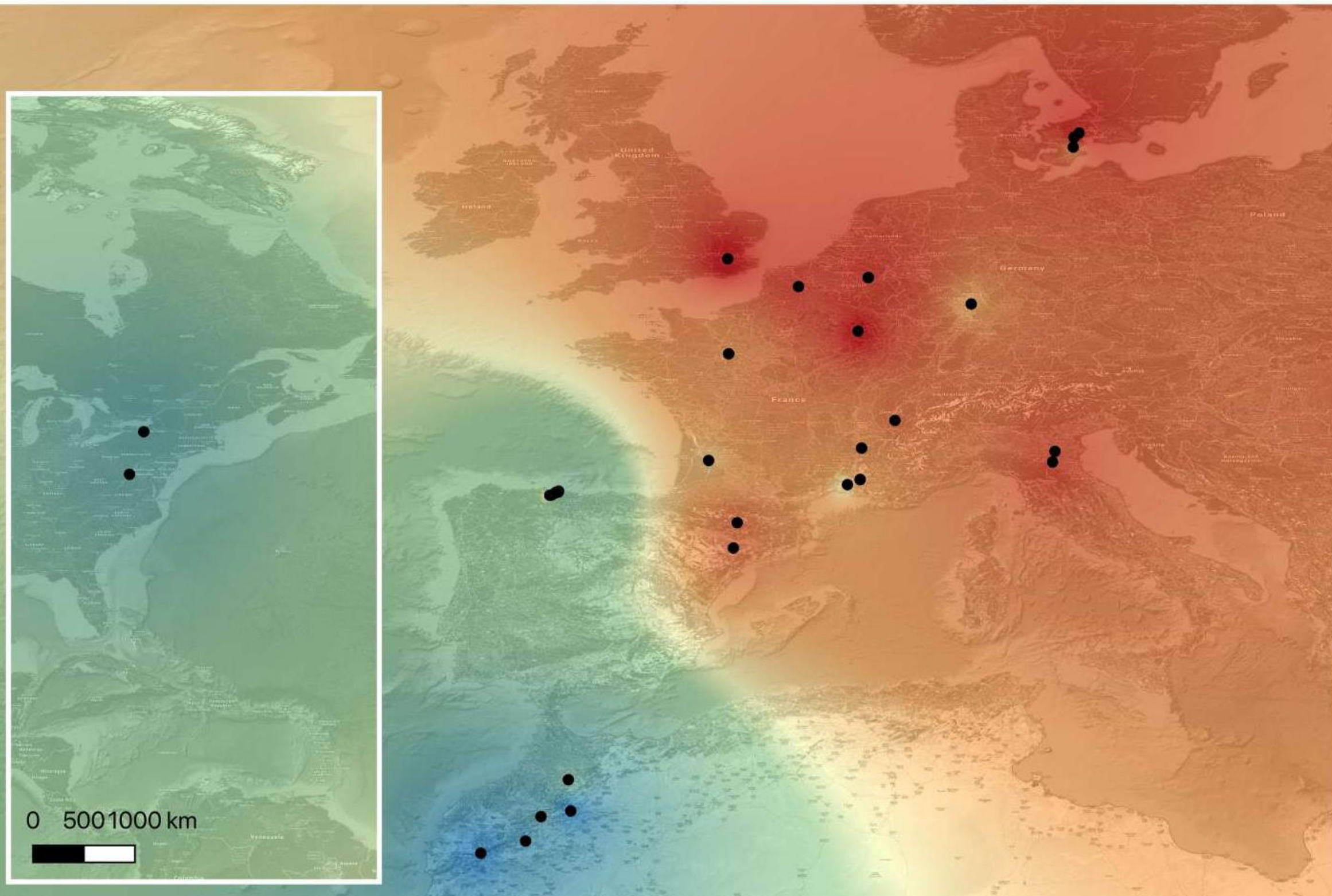


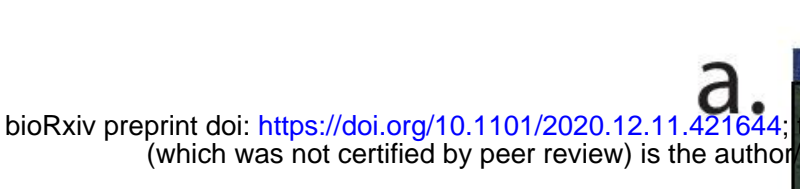

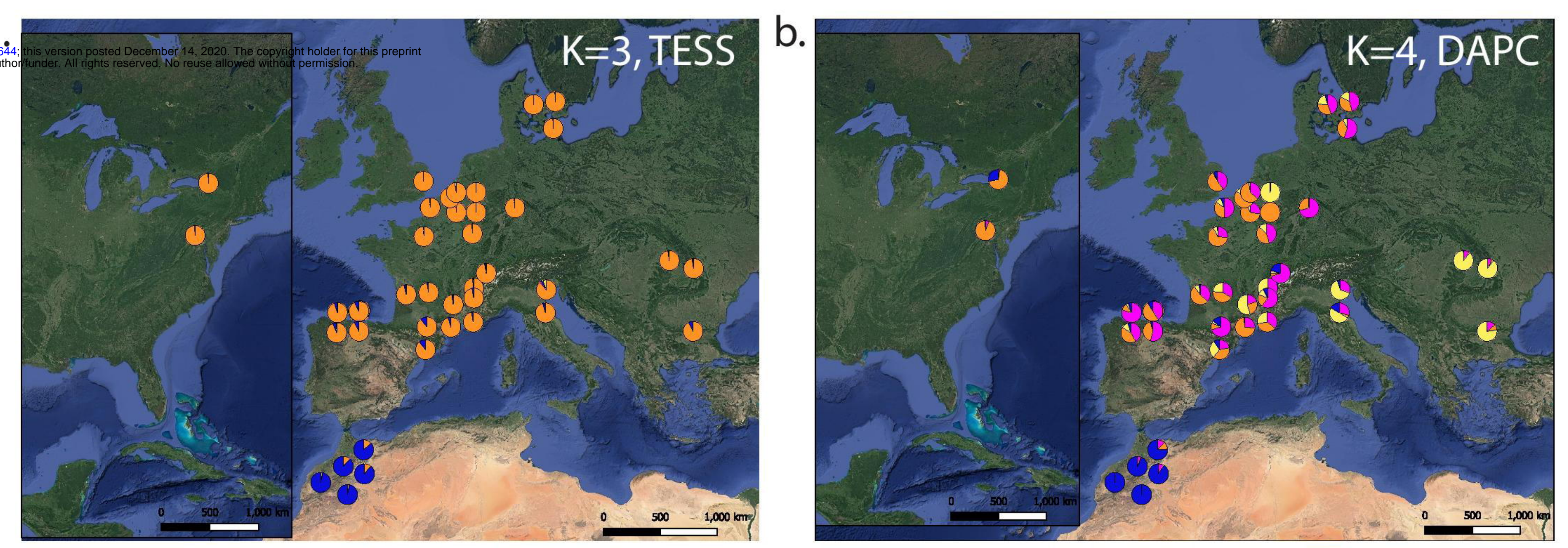

c.

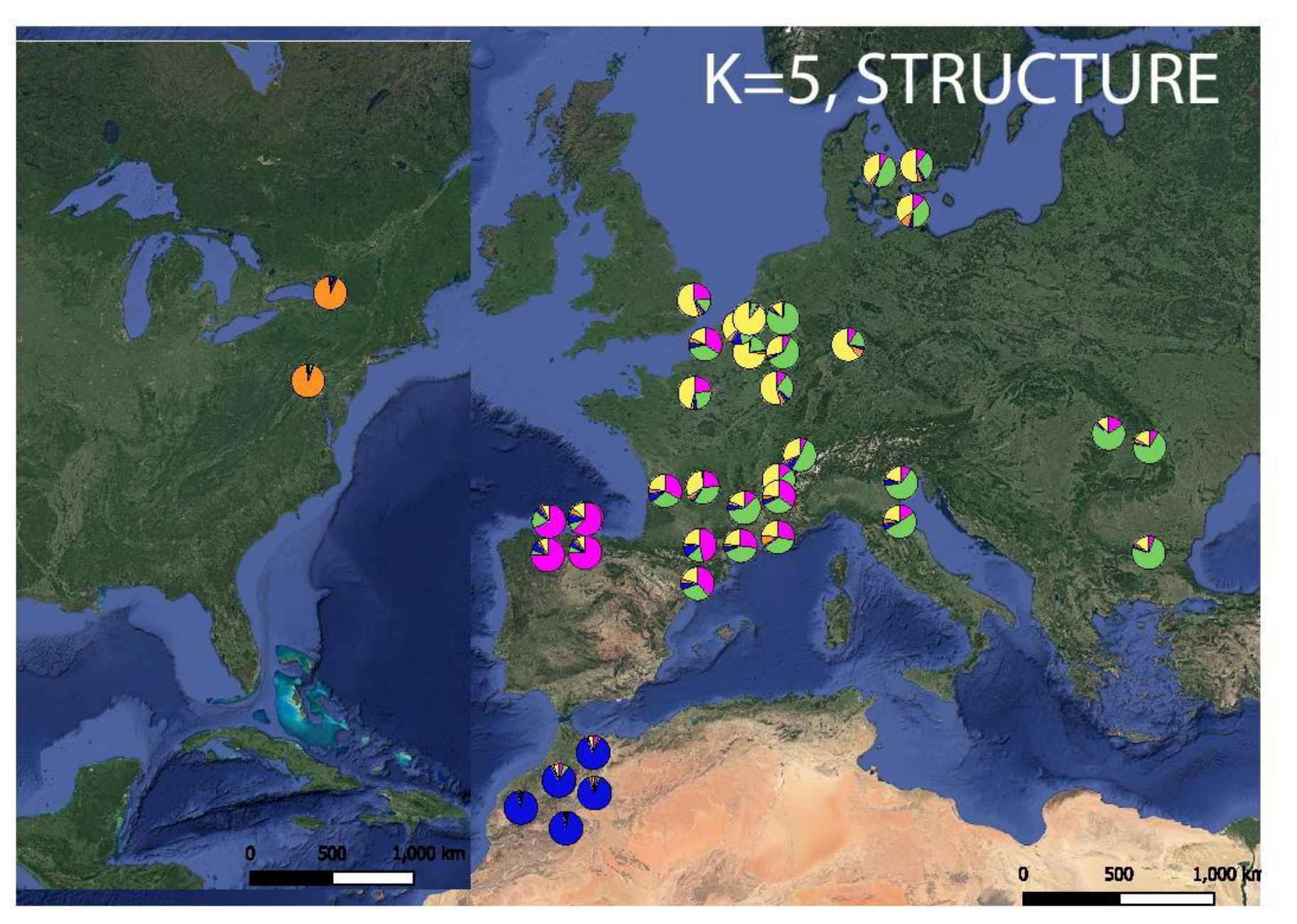

d.

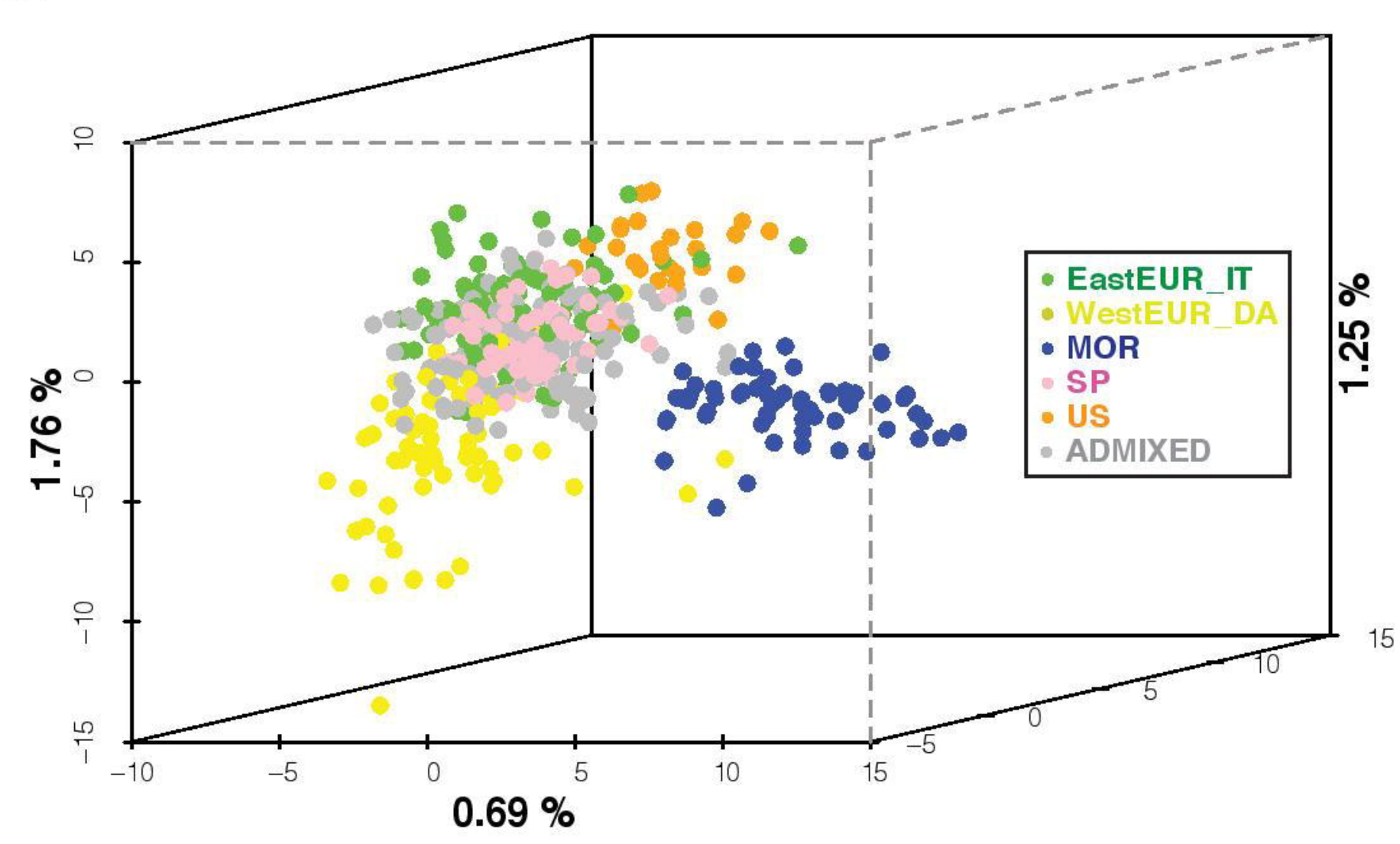

e.

Western Europe and Denmark

Spain

Eastern Europe

and Italy

Morocco

US

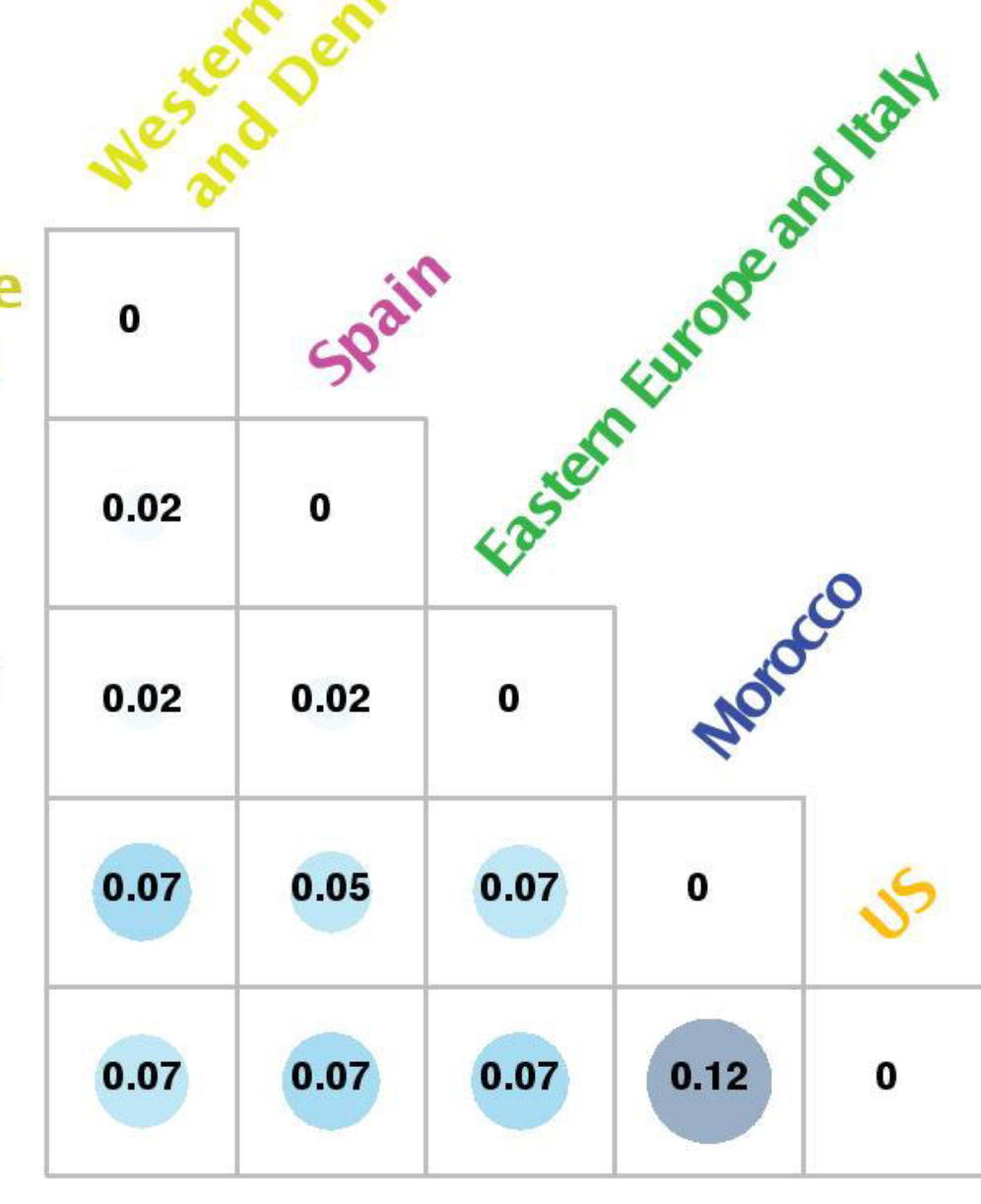

